Review

\title{
Towards Improved Airborne Fire Detection Systems Using Beetle Inspired Infrared Detection and Fire Searching Strategies
}

\author{
Herbert Bousack ${ }^{1, *}$, Thilo Kahl ${ }^{2}$, Anke Schmitz ${ }^{2}$ and Helmut Schmitz ${ }^{2}$ \\ 1 Peter Grünberg Institut, Forschungszentrum Jülich, 52425 Jülich, Germany \\ 2 Institut für Zoologie, Universität Bonn, Meckenheimer Allee 169, 53115 Bonn, Germany; \\ E-Mails: thilo.kahl@uni-bonn.de (T.K.); ankeschmitz@uni-bonn.de (A.S.); \\ h.schmitz@uni-bonn.de (H.S.) \\ * Author to whom correspondence should be addressed; E-Mail: h.bousack@fz-juelich.de; \\ Tel.: +49-246-161-6242; Fax: +49-246-161-8733.
}

Academic Editor: Gijs Krijnen

Received: 31 March 2015 / Accepted: 29 May 2015 / Published: 16 June 2015

\begin{abstract}
Every year forest fires cause severe financial losses in many countries of the world. Additionally, lives of humans as well as of countless animals are often lost. Due to global warming, the problem of wildfires is getting out of control; hence, the burning of thousands of hectares is obviously increasing. Most important, therefore, is the early detection of an emerging fire before its intensity becomes too high. More than ever, a need for early warning systems capable of detecting small fires from distances as large as possible exists. A look to nature shows that pyrophilous "fire beetles" of the genus Melanophila can be regarded as natural airborne fire detection systems because their larvae can only develop in the wood of fire-killed trees. There is evidence that Melanophila beetles can detect large fires from distances of more than $100 \mathrm{~km}$ by visual and infrared cues. In a biomimetic approach, a concept has been developed to use the surveying strategy of the "fire beetles" for the reliable detection of a smoke plume of a fire from large distances by means of a basal infrared emission zone. Future infrared sensors necessary for this ability are also inspired by the natural infrared receptors of Melanophila beetles.
\end{abstract}

Keywords: forest fire; fire detection; infrared sensor; early warning system; pyrophilous insect; Melanophila beetle 


\section{Introduction}

In many regions of the world forest fires are a serious threat, especially in populated areas resulting in losses of human lives, destroyed houses and devastated forests. The economic losses per year in the United States were about $\$ 2,000-\$ 3,500$ million in the few last years; for Spain, Portugal and Greece losses were in between $\$ 1,700$ and $\$ 2,000$ million [1]. In Australia, the loss per year is approximately $\$ 6,625$ million, which is about $1.15 \%$ of the country's Gross Domestic Product [2]. Global climate change will aggravate the problem because of the extension of drought periods [3].

It is obvious that early detection of forest fires and a fast deployment of firefighting can avoid major losses. Various forest fires detection techniques exist: human based observation from fire towers, satellite systems, optical cameras on camera towers and wireless sensor networks (WSN). The WSN uses a large number of small, low cost sensors to measure temperature, pressure and humidity. The sensors are densely distributed and in the case of fire detection, a signal is transmitted to a nearby receiver that switches on the closest internet protocol camera to get real images [4]. A recent comparison of the fire detection techniques came to the conclusion that WSN are the best available solution regarding efficiency and fire localizing accuracy [5]. However, WSN needs a large number of battery-operated sensors with low power consumption. A novel system uses unmanned aerial systems, such as remote controlled mini-helicopters, equipped with visual and infrared cameras [6]. The main task is to locate a new fire and gather data about the shape of the fire front, rate of spread, etc. The system was successfully tested in field experiments. A disadvantage is that the helicopter must investigate a suspicious observation from a close distance to exclude false alarms and therefore needs to cover long flight paths to exclude errors.

A look into the animal kingdom shows specialized creatures have existed for millions of years and have solved similar problems. The wood boring larvae of jewel beetles of the genus Melanophila totally depend on burnt wood. In order to be able to reproduce, the adult beetles must locate forest fires from distances as large as possible because the outbreak of a fire is unpredictable. Here, the beetles have the same problem as the firefighters: from their respective observation point. They must exclude false alarms to avoid energy consuming flights to, e.g., a deep hanging cloud bank simulating the smoke plume of a fire. As a special adaptation to their pyrophilous way of life, Melanophila beetles have developed infrared (IR) receptors. Thus it is evident that the sensory system and the strategy of the beetles to identify forest fires can be used as an interesting model for an innovative airborne fire detection system: the beetlecopter.

\section{Photomechanic IR Receptors in Pyrophilous Melanophila Beetles}

Discrete IR receptors are extremely rare in insects. To date, IR receptors have only been found in a small group of highly specialized insects that approach ongoing forest fires and, therefore, have been termed pyrophilous [7]. Actually, only 17 pyrophilous insect species from four genera are known to possess IR sensory organs (Table 1). Compared to the amount of known insect species (roughly one million), this is a negligible number. Nevertheless, a closer look at the IR receptors in the four genera reveals an astounding diversity. At least three fundamentally different types of receptors can be identified: A pair of prothoracic discs covered with numerous tiny sensilla in Acanthocnemus nigricans, 
two pairs of roundish abdominal IR organs in Merimna atrata, and the so-called photomechanic IR sensilla found in Melanophila beetles and a few pyrophilous Aradus bugs.

With regard to the functional principles, two categories exist: bolometer-like receptors in Acanthocnemus and Merimna and photomechanic sensilla in Melanophila and Aradus (cf. Table 1). The different shape as well as the location at different positions on the thorax or the abdomen provides strong evidence that IR receptors in the four genera have evolved independently from each other. Therefore, it can be stated that no "standard" IR receptor seems to exist in insects. However, a substantial similarity exists between the photomechanic IR sensilla found in Melanophila beetles and Aradus bugs. Because the lineages of beetles and bugs most likely separated in the Permian period, about 270 million years ago, there is little doubt that IR sensilla developed independently in both genera. In this particular case, the independent development has led to more or less the same type of mechanoreceptor based IR sensillum, which is called photomechanic.

Because the photomechanic IR receptors of jewel beetles of the genus Melanophila seem to be the most sensitive insect IR receptors, these receptors are chosen as models for bio-inspired technical sensors and will be dealt with below in more detail.

\section{Structure and Function of Melanophila IR Receptors}

Beetles of the genus Melanophila inhabit nearly all continents except Australia [8] and use fire-killed trees as food for their larvae. For this reason the adult beetles fly to ongoing forest fires [9]. The freshly burnt area serves as a meeting place for both sexes and, after copulation, the females start to deposit their eggs under the bark of burnt trees. After hatching, the larvae feed on the wood of the fire-killed trees and the new generation of beetles will emerge one or two years later. It has been reported that Melanophila species breed in a variety of burnt conifers as well as in several species of scorched deciduous trees [10,11].

The IR receptors are situated in two pit organs, which are located on the metathorax ( $c f$. Table 1). Each IR organ houses about 70 IR receptors, called sensilla, which are closely packed together at the bottom of the pit (Figure 1a), [12,13]. From the outside, a single sensillum can be recognized by a hemispherical dome with a diameter of about $15 \mu \mathrm{m}$. The dome is built by a thin but hard exocuticle (Figure $1 \mathrm{~b}, \mathrm{c}$ ), which represents the outer boundary of a spherical internal cavity. The cavity is almost completely filled out by a tiny cuticular sphere with a diameter of about $10 \mu \mathrm{m}$ (Figure 1b,c). Based on transmission electron microscopic observations, Vondran et al. (1995) described the sphere as consisting three different zones: (i) an outer lamellated mantle (ls in Figure 1c); (ii) an intermediate layer of unstructured cuticle revealing many irregularly arranged nanocanals and microcavities (mc in Figure 1c); and (iii) an innermost central zone where the cuticle appears uniform except for some spots of higher electron density (cz in Figure 1c). The sphere is connected to the vertex of the outer cuticular dome by a small cuticular stalk and the narrow gap surrounding the sphere is filled out by leaf like extensions of at least two enveloping cells filled with aqueous protoplasm. From below, the sphere is innervated by a single sensory cell ( $d$ in Figure $1 \mathrm{c}$ ). As a prominent feature, the outermost tip of the dendrite is located inside an inner pressure chamber in the sphere (ipc in Figure 1b,c). All morphological as well as all physiological data available so far have demonstrated that this cell is a ciliary mechanoreceptor [13-15]. 
Table 1. Infrared receptors in pyrophilous insects.

\begin{tabular}{|c|c|c|c|c|}
\hline Parameter & $\begin{array}{l}\text { "Little Ash Beetle" } \\
\text { Acanthocnemus nigricans } \\
\text { Only species in the genus }\end{array}$ & $\begin{array}{l}\text { "Australian Fire Beetle" } \\
\text { Merimna atrata } \\
\text { Only species in the genus }\end{array}$ & $\begin{array}{c}\text { "Black Fire Beetle" } \\
\text { Melanophila spec. } 11 \text { species }\end{array}$ & $\begin{array}{l}\text { "Pyrophilous Flat Bugs" } \\
\text { Aradus spec. } 4 \text { IR sensitive species } \\
\text { in the genus Aradus (200 species) }\end{array}$ \\
\hline Systematic position & Beetle (family: Acanthocnemidae) & \multicolumn{2}{|c|}{ Jewel beetles (family: Buprestidae) } & Flat bugs (family: Aradidae) \\
\hline $\begin{array}{l}\text { Ventral habitus } \\
\text { IR organs/receptors } \\
\text { indicated in yellow } \\
\text { Legs omitted } \\
\text { L: body length }\end{array}$ & $\mathrm{L}: 4 \mathrm{~mm}$ & $\mathrm{~L}: 20 \mathrm{~mm}$ & $\mathrm{~L}: 10 \mathrm{~mm}$ & $\mathrm{~L}: 4 \mathrm{~mm}$ \\
\hline Position of IR receptor & prothorax & abdomen & metathorax & pro-/mesothorax \\
\hline \multicolumn{5}{|l|}{$\begin{array}{l}\text { Picture of IR organ } \\
\text { or single sensillum }\end{array}$} \\
\hline & $\begin{array}{l}\text { Left IR organ (sensory disc } \\
\text { with numerous tiny sensilla) }\end{array}$ & $\begin{array}{c}\text { Left anterior IR organ } \\
\text { (trough-shaped cuticular } \\
\text { depression) }\end{array}$ & $\begin{array}{l}\text { Single IR sensillum } \\
\text { (about } 70 \text { dome-shaped } \\
\text { sensilla in a sensory pit) }\end{array}$ & $\begin{array}{l}\text { Single IR sensillum (dome-shaped } \\
\text { sensilla interspersed between hair } \\
\text { mechanoreceptors) }\end{array}$ \\
\hline Mode of operation & \multicolumn{3}{|c|}{ Bolometer (in Merimna with additional photomechanic unit) } & hanic receptors \\
\hline
\end{tabular}



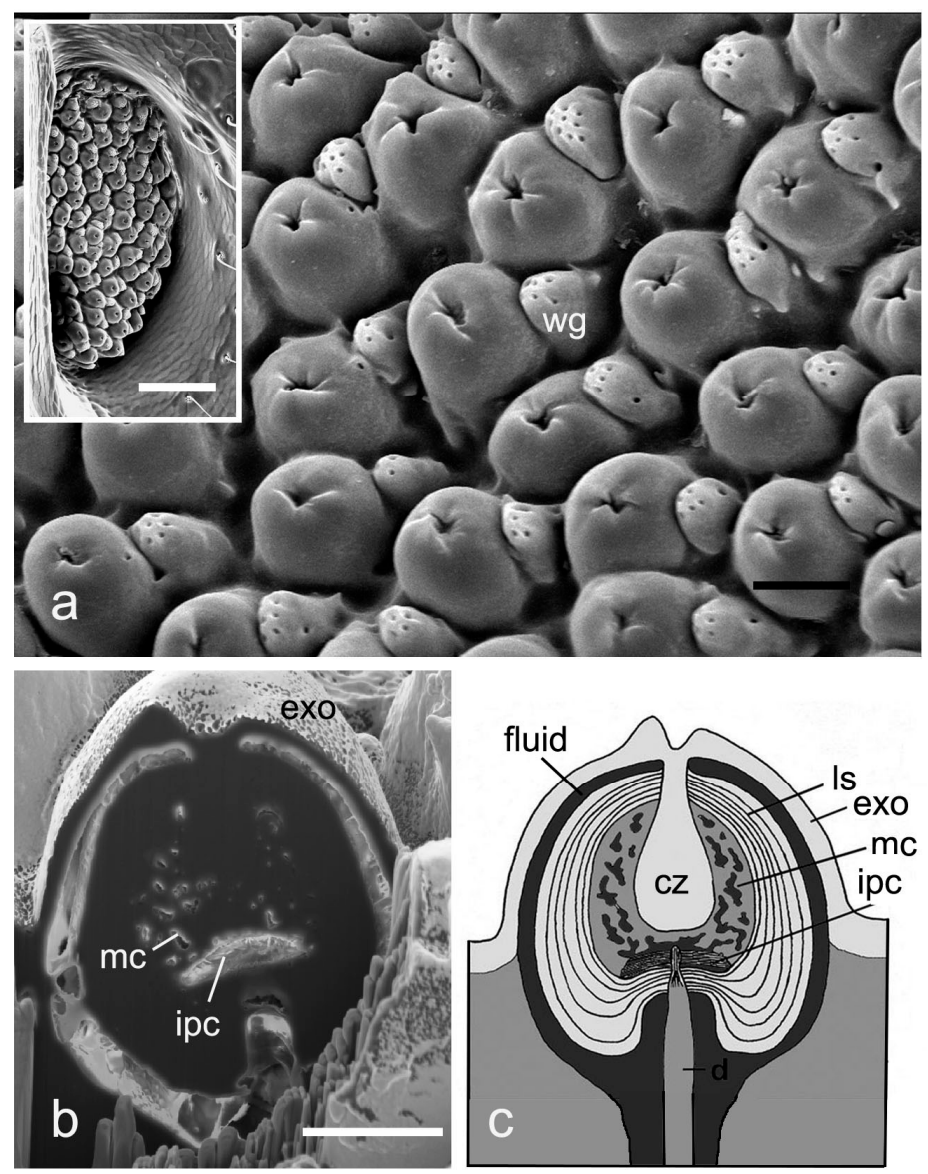

Figure 1. Infrared (IR) organ of Melanophila acuminata. (a) Dome-shaped IR sensilla at the bottom of a pit organ (whole organ shown in the inset). Each sensillum is accompanied by a smaller wax gland (wg) characterized by tiny pores. Bar: $15 \mu \mathrm{m}$ (Inset $100 \mu \mathrm{m}$ ). (b) Single IR sensillum centrally opened by focused ion beam (FIB). Specimen was air-dried; therefore only the cuticle is preserved. Microcavities $(\mathrm{mc})$ of the intermediate layer and the inner pressure chamber (ipc) can be discerned inside the sphere. exo: exocuticular outer dome. Bar: $5 \mu \mathrm{m}$. (c) Schematic drawing of a photomechanic IR sensillum covered by an outer dome of hard exocuticle (exo). The tip of the dendrite (d) is suspended by fine filaments inside the inner pressure chamber (ipc), which communicates with the fluid in the microcavities $(\mathrm{mc})$ of the intermediate layer. Any increase in fluid pressure is transferred onto the dendritic membrane. (ls): lamellated exocuticular shell of the sphere.

According to the current conception of how IR radiation may be converted into a mechanical event perceivable by the mechanoreceptive cell, absorbed IR radiation heats the sphere causing an increase in pressure in the fluid filled system of communicating microcavities inside the sphere. Because the outer lamellated mantle consists of a hard exocuticle reinforced by layers of chitin fibers [16], the only compliant structure in the sphere is the olive-shaped tip of the dendrite in the inner pressure chamber, which becomes slightly squeezed by the minute increase in pressure ( $c f$. Figure 1c). This membrane displacement is the adequate stimulus for a mechanoreceptor $[17,18]$.

Up to now, the crucial question from which distances a Melanophila beetle can detect a fire by IR reception cannot be answered. Extracellular electrophysiological recordings obtained by inserting a metal electrode between the IR sensilla have revealed a maximum sensitivity in the wavelength range 
2.8-3.5 $\mu \mathrm{m}$. This corresponds to the emission maximum of a forest fire [19]. Sensilla show a fast and strictly phasic response to heating [15] and a threshold sensitivity of $500 \mu \mathrm{W} / \mathrm{cm}^{2}$ was found [14]. It has been calculated that this sensitivity would enable a beetle to detect a 20 hectare forest fire from a distance of about $12 \mathrm{~km}$ [14]. However, because the metal electrode may have sucked considerable amounts of heat energy away from the sensilla, this threshold is probably underestimated. A recent in depth modeling of a big historic oil tank fire, which attracted untold numbers of Melanophila consputa in California ninety years ago [20], suggested a much higher sensitivity of the IR receptors [21]. The analysis of the geographical conditions around the tank fire yielded the result that most beetles must have become aware of this fire from a distance of $130 \mathrm{~km}$. If IR radiation really was a crucial cue used by the beetles to detect the fire, this would result in a sensitivity of a few $\mathrm{nW} / \mathrm{cm}^{2}$ [21]. In principle this would mean that the IR receptors of Melanophila beetles can even compete with technical high sensitivity quantum IR sensors, which have to be cooled, e.g., with liquid nitrogen, to suppress thermal noise. However, additional mechanisms like active amplification and effective noise suppression have to be postulated to make this high sensitivity imaginable (see Section 4).

\section{Detection Distances of Forest Fires by Melanophila Beetles}

A forest fire is influenced by a lot of parameters, such as the type and condition of the forest, weather conditions, etc. For calculation of the radiation heat flux of the fire received at a chosen distance, an established model of the emissive power of the fire is necessary that considers these parameters.

Actually, a broad experience exists to predict the radiant heat flux from forest fires used in models of fire spread and fire intensity, to establish safety distances for firefighters, and for fire protection of houses [22-24]. Commonly a model is used where an opaque box located at the base of the flame front represents the flame front (Figure 2). The height of the box, $L_{\mathrm{F}}$, represents the mean height of the flame front; and $W_{\mathrm{F}}$ is the width of the flame front. The inclination of the flames depends on the strength of the wind velocity behind the flame front, and is described by the angle $\varphi$.
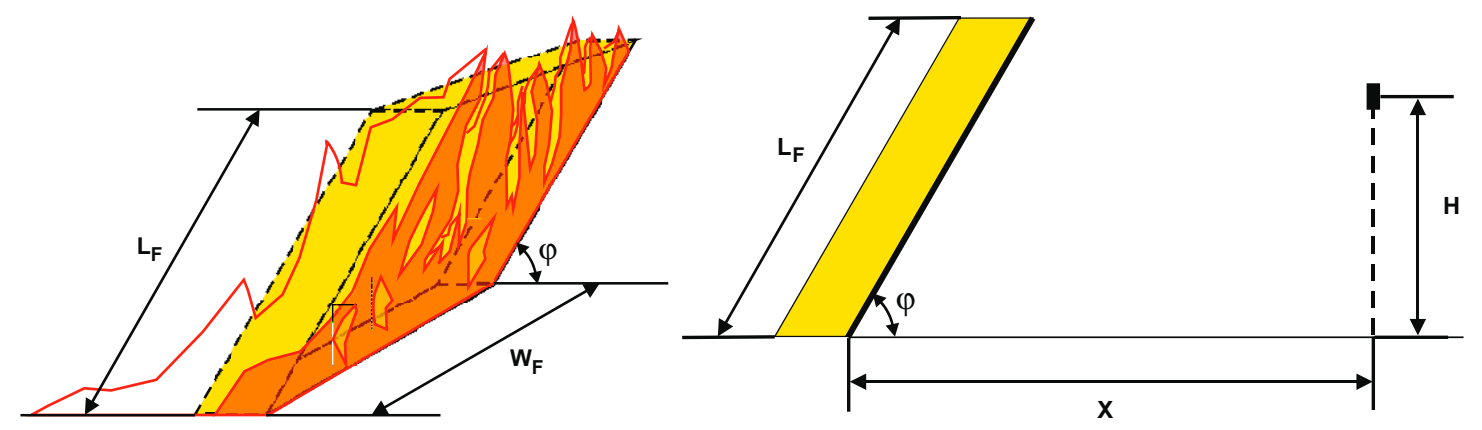

Figure 2. (Left) Model of a radiating fire front represented by a cuboid with the width $W_{\mathrm{F}}$ of the fire front and the flame height $L_{\mathrm{F}}$. (Right) The heat flux will be calculated in the distance $x$ from the fire front and at a point with height $\mathrm{H}$ above ground representing the altitude of the beetle.

The radiant heat flux received $q_{\text {rad }}$ by a small element at a distance $x$ away from the emitting front face of the cuboid representing the flame front can be calculated with [23,25]:

$$
q_{\mathrm{rad}}(x, \lambda)=\left(\varepsilon \cdot \sigma \cdot T^{4}\right) \cdot F_{1 \rightarrow 2} \cdot \tau(x, \lambda)
$$


where, $\varepsilon$ : emissivity of the radiating surface; $\lambda$ : wavelength; $\sigma$ : Stefan-Boltzmann constant; $T$ : temperature of flame surface; $F_{1 \rightarrow 2}$ : configuration factor or geometrical view factor between the radiating surface and the receiving surface; and $\tau(x, \lambda)$ : transmittance of atmosphere.

Equation (1) is based on some important conditions that must be taken into account. The emissivity $\varepsilon$, is not constant and depends on the flame thickness, e.g., $\varepsilon$ can be assumed to be 0.9-1.0 for a flame thickness larger than $3 \mathrm{~m}$ [26]. Equation (1) also requires a constant temperature over the radiating surface. This assumption can only be a rough approximation due to the complex combustion conditions in a flame front, e.g., the flame temperature over a flame height of $6 \mathrm{~m}$ from varies from about 700 to $1300 \mathrm{~K}$ [27].

The view factor, $F_{1 \rightarrow 2}$, is a dimensionless ratio describing the fraction of radiation that arrives at the area of an object 2 as part of the radiation diffusely emitted by the area of an object 1 . It varies between 1 (object 2 very close to object 1 ) and 0 (object 2 very far away from object 1 ). For the geometry of the emitting surface shown in Figure 3, the view factor regarding a small receiving area can be calculated using the equation suggested in [28]. The view factor is independent from the height $H$ of the receiving element about ground level for larger distances $x$. This means that the received amount of IR radiation of the beetles is only slightly affected by their flight altitude.

For the calculation of the view factor, $F_{1 \rightarrow 2}$, the flame height, $L_{\mathrm{F}}$, the flame width, $W_{\mathrm{F}}$, and the wind velocity must be known. The flame width seems to be of minor influence on the radiation intensity near the flame front [29]. Here the determination of the flame height, $L_{\mathrm{F}}$, is the critical factor because characteristic values of the forest must be taken into account.

For forests the flame height, $L_{\mathrm{F}}(\mathrm{m})$, can be calculated with [30]:

$$
L_{\mathrm{F}}=\frac{13 \cdot R+0.24 \cdot W}{2}
$$

with: $R(\mathrm{~km} / \mathrm{h})$ : rate of flame spread, $W$ : overall fuel load, $W=25-40 \mathrm{t} / \mathrm{ha}$ [30].

The rate of flame spread $R$ depends on several factors regarding the atmospheric conditions, e.g., humidity, temperature, wind, amount of precipitation before the fire occurred, and characteristics of the forest and structure of the grounds, such as maximum fuel load, height of trees, understory, and slope of ground. Different models for the calculation of the rate of flame spread are discussed in [31]. Here a model is used that was developed for the eastern parts in Australia [32].

$$
R=0.0012 \cdot \mathrm{FDI} \cdot w \cdot e^{0.069 \times \text { slope }}
$$

where, FDI: Fire Danger Index, $w$ : surface fuel load, $w \approx W-10$ t/ha [30], slope $\left(^{\circ}\right)$ : effective slope of ground.

The fire intensity $I$ per length of the flame front is [33]:

$$
I=H \cdot W \cdot \frac{R}{36}
$$

where, $H(\mathrm{~kJ} / \mathrm{kg})$ : heat of combustion.

The Fire Danger Index FDI ranges in classes from $<5$ (low danger) to $>50$ (extreme danger) and can be calculated as a function of the many factors mentioned above [32]. Equation (3) predicts the rate of spread reasonable well at low wind speeds smaller than $12.5 \mathrm{~km} / \mathrm{h}$. For higher wind speeds this and other models underestimate the rate of spread [34]. 
The influence of the transmittance of atmosphere depends on the distance to the forest fire, the humidity of the air and airborne particles like dust and smoke and can be calculated with equations expressed in [21].

For the estimate of the maximal detection distance of the beetle, one has to make some assumptions regarding the forest, the weather and atmospheric conditions and the fire. One possibility is to choose input values that yield maximum or minimum values for the detection distance. One drawback of this calculation is the uncertainty of the input parameters, e.g., flame temperature, emissivity and weather conditions, etc. Here combinations can be chosen that result in higher or lower values, but they are less probable. This disadvantage can be overcome by the use of input parameters with probability distributions and a stochastic model which employs a Monte Carlo method [35]. With this method, a result can be achieved that includes a more precise detection distance and its probability. The input parameters with a uniform distribution are shown in Table 2.

Here a forest or open woodland with a vegetation height of 2-30 m of eucalypts and acacias is chosen; the data in Table 3 are mostly in accordance with [33] and [35]. The weather conditions are hot, long time without rain and the Fire Danger Index (FDI) with extreme danger of fire [36]. The heat-receiving element is assumed to be at a height of $100 \mathrm{~m}$ over ground, representing the altitude of the beetle. The calculation of radiant heat flux as a function of distance to the fire were performed for two different fire situations: a larger fire with a flame front between 90 and $110 \mathrm{~m}$ and a small starting fire with an flame front between 10 and $30 \mathrm{~m}$. Table 3 shows the mean values of the parameters from Equations (1)-(4).

Figure 3 shows an example the probability distribution of the radiation heat flux of a flame front (90-110 m) at a distance to the fire of $50 \mathrm{~km}$ with 5 and 95 percentile and mean value. The dependence of the radiation heat flux as a function of the fire distance for the flame front $90-110 \mathrm{~m}$ and $10-30 \mathrm{~m}$ is shown in Figures 4 and 5. The blue field indicates the sensitivity of the beetle determined in [21]. With regard to the mean values of the radiation heat flux, the detection distance of the large fire (flame front 90-110 m) is larger than $130 \mathrm{~km}$ and the detection distance of the starting fire (flame front 10-30 m) is about $100 \mathrm{~km}$.

For the detection of this radiation values with IR sensors the noise level due to temperature fluctuations must be kept in mind. The minimum detectable radiant heat flux of an uncooled IR-sensor is [37]:

$$
\begin{aligned}
& q_{\text {min,noise }}=\frac{\sqrt{\frac{\Delta f}{A_{Z}}}}{D^{*}} \\
& D^{*}=\frac{1}{\sqrt{16 \cdot \varepsilon \cdot k_{\mathrm{B}} \cdot \sigma_{\mathrm{S}} \cdot T^{5}}}
\end{aligned}
$$

with: $D^{*}$ : specific detectivity of the sensor; $\varepsilon$ : emissivity of sensor surface; $\sigma_{\mathrm{S}}=5.67040 \times 10^{-8} \mathrm{~W} / \mathrm{m}^{2} \cdot \mathrm{K}^{4}$ : Stefan-Boltzmann constant; $k_{\mathrm{B}}=1.3806504 \times 10^{-23} \mathrm{~J} / \mathrm{K}$ : Boltzmann constant; $T$ : temperature of target and heat sink; and $\Delta f$ : bandwidth.

The specific detectivity $D^{*}$ of commercially available IR sensors is, e.g., $0.9 \times 10^{8} \mathrm{~cm} \cdot \mathrm{Hz}^{0.5} / \mathrm{W}$ with a sensitive area $A z$ of $0.5 \mathrm{~mm}^{2}$ (Thermopile TPD 1 T 0216 IRA, Perkin Elmer, Waltham, MA, USA [38]) yielding a bandwidth of a minimal detectable radiant heat flux $(\Delta f=10 \mathrm{~Hz}, \varepsilon=1)$ of $5 \times 10^{-3} \mathrm{~W} / \mathrm{m}^{2}$. This means that without using any methods to detect the fire signals below this noise level, the detection distance is reduced for the large fire (flame front 90-110 m) to $42 \mathrm{~km}$ and the detection distance of the starting fire (flame front $10-30 \mathrm{~m}$ ) to $21 \mathrm{~km}$. The detection signals below the noise 
level is possible with stochastic resonance [39,40] in connection with adaptive signal processing [41,42] or phase space projection [43]. The proposed active amplification mechanism described above also seems suitable to extract small signals from noise allowing a detection of the large fire from a distance of $130 \mathrm{~km}$ and a detection of the small starting fire from a distance of $90 \mathrm{~km}$ ( $c f$. Table 3 ).

Table 2. Input parameters with uniform distribution for the Monte Carlo method.

\begin{tabular}{cc}
\hline Parameter & Value \\
\hline Emissivity flame $\varepsilon$ & $0.7-1.0$ \\
Flame temperature $T$ & $800-1200^{\circ} \mathrm{C}$ \\
Heat of combustion $H$ & $17,000-18,600 \mathrm{~kJ} / \mathrm{kg}$ \\
Surface fuel load $w$ & $8-25 \mathrm{t} / \mathrm{ha}$ \\
Fire Danger Index FDI & $50-75$ \\
Slope of ground & $0^{\circ}$ \\
Visibility atmosphere & $7-13 \mathrm{~km}$ \\
Temperature air & $25-30^{\circ} \mathrm{C}$ \\
Humidity & $25 \%-35 \%$ \\
Wind velocity & $30-60 \mathrm{~km} / \mathrm{h}$ \\
\hline
\end{tabular}

Table 3. Output parameters (5th and 95 th percentile) calculated according to the Monte Carlo method with the input parameters from Table 2.

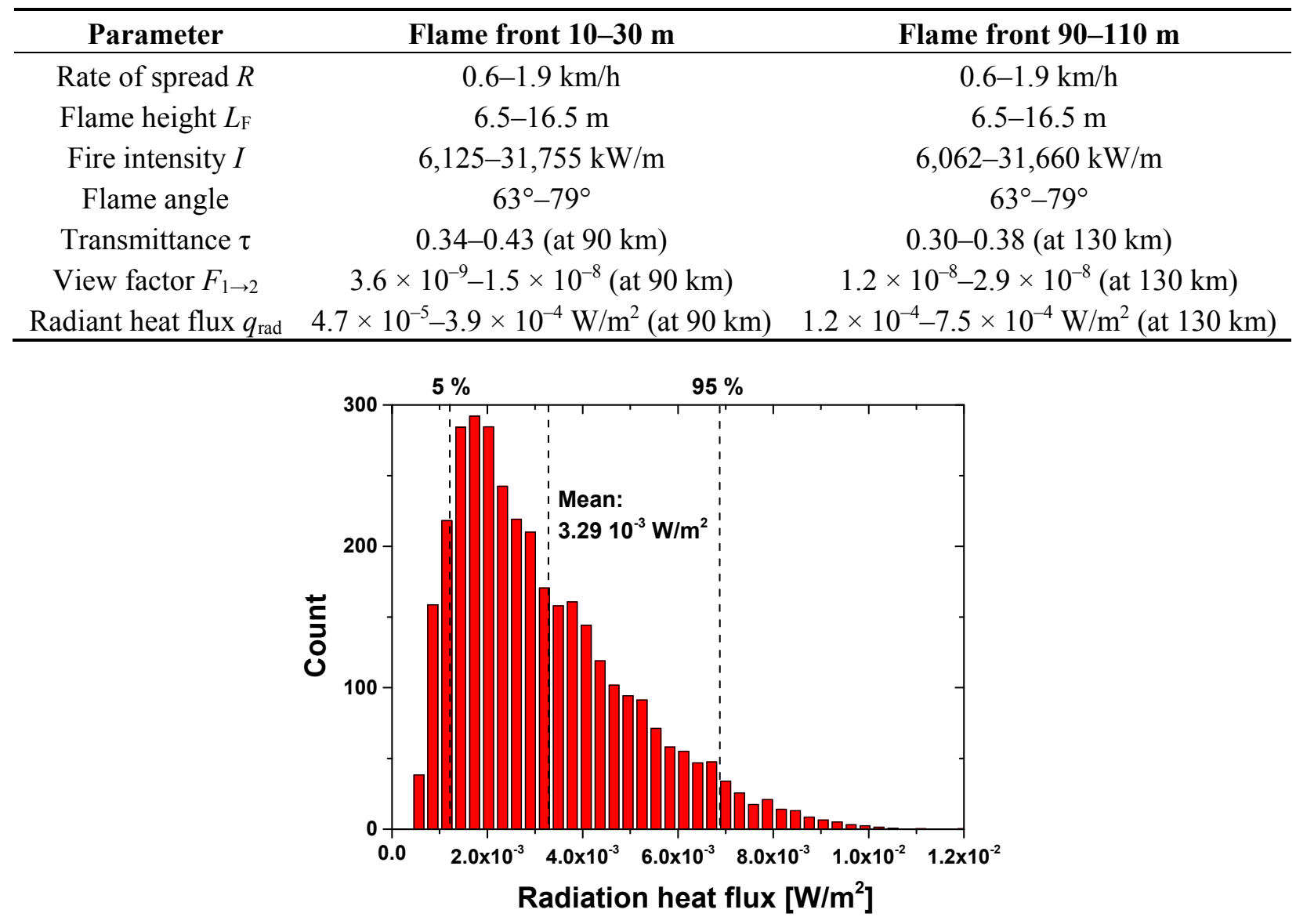

Figure 3. Radiation heat flux probability distribution (flame front 90-110 m) at a fire distance of $50 \mathrm{~km}$. 


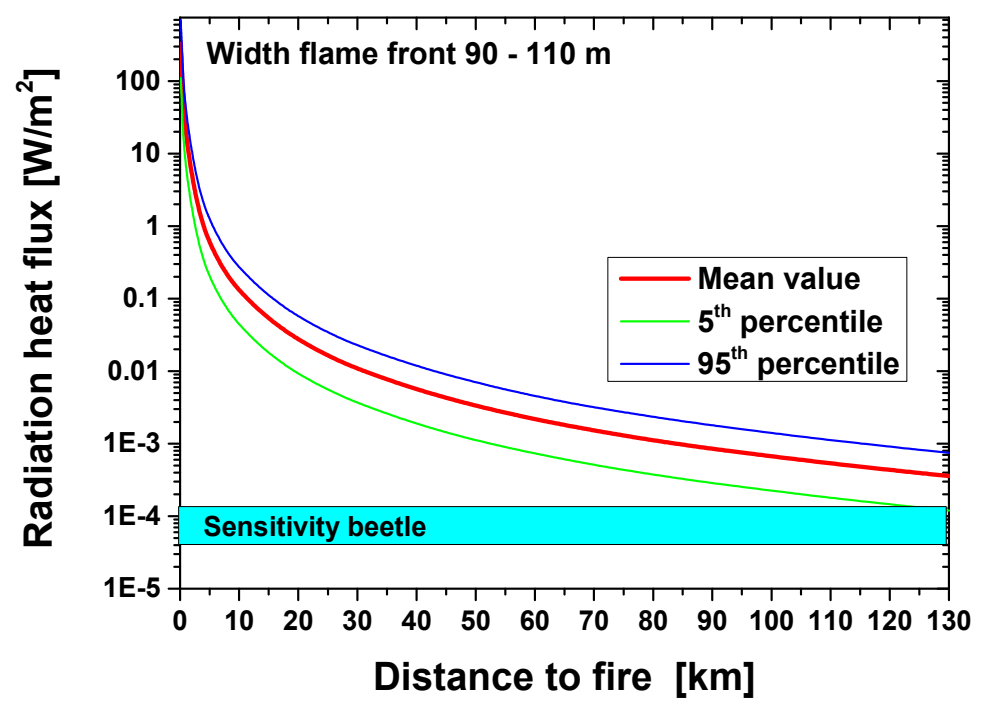

Figure 4. Radiation heat flux (flame front $90-110 \mathrm{~m}$ ) as function of the fire distance.

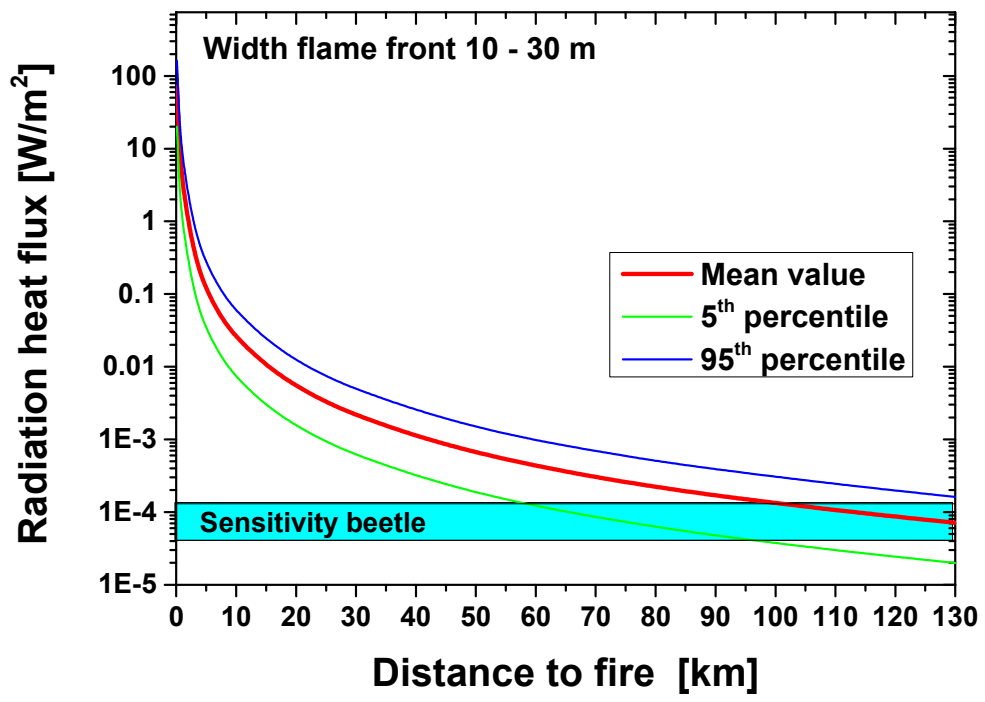

Figure 5. Radiation heat flux (flame front $10-30 \mathrm{~m}$ ) as function of the fire distance.

\section{Evaluation of a Biomimetic IR Sensor Based on the Melanophila IR Receptor}

\subsection{Sensor Model}

The reconstruction of the IR sensillum in Figure 1c is reminiscent of a well know IR sensor, the Golay cell [44]. This sensor consists of an internal gas-filled cavity, which is closed on one side by an IR-permeable window and on the other side by a thin membrane. IR radiation enters through the window and heats up the gas by absorption. The deflection of the membrane caused by the expanding gas can be read by an optical system [44]. Very small Golay sensors are already produced in silicon microstructure technology using a capacitive detector [45] or a tunneling displacement transducer [46] as read out for the membrane deflection. To enhance the IR absorption in the gas, the cavity is equipped with an additional absorber, e.g., a thin plastic mesh. Reflective walls of the cavity are another means to enhance absorption. The temperature changes of the gas caused by the absorbed IR radiation are in the $\mathrm{mK}$-range or lower, this means that very tiny membrane deflections must be 
measured in the nm-range. Because of slow variations of the ambient temperature in the range of a few $\mathrm{K}$, a high-pressure increase - compared to IR measurements - will occur in the cavity and possibly destroy the membrane. Therefore it is necessary to integrate a leak, which compensates this influence of ambient temperature changes by an exchange of the gas with a reference volume or a reference pressure.

In order to analyze the IR sensor based on the IR sensillum, a simple set-up is used (see Figure 6). Similar to the sensillum, the sensor contains an internal water-filled cavity. The exchange of the fluid, a liquid instead of gas, is a major difference of the sensillum compared to the Golay sensor. The cavity of the technical sensor is closed on one side by a window and on the other side by a thin membrane. The IR radiation being absorbed produces a change in pressure or volume, respectively, due to the change of the state of the fluid. The deflection of the membrane caused by this pressure increase can be read out by, e.g., a capacitive detector or a tunneling displacement transducer.

In the Melanophila IR receptor, the inner sphere is enclosed by a thin layer of fluid, which is always at ambient pressure. Therefore, the nanocanals in the shell of the sphere allow the exchange of fluid in and out of the microfluidic compartment in the sphere. Thus, any internal pressure change that may be caused by the slowly changing ambient temperature can be compensated in a similar way to the compensation leak of a Golay sensor.

IR

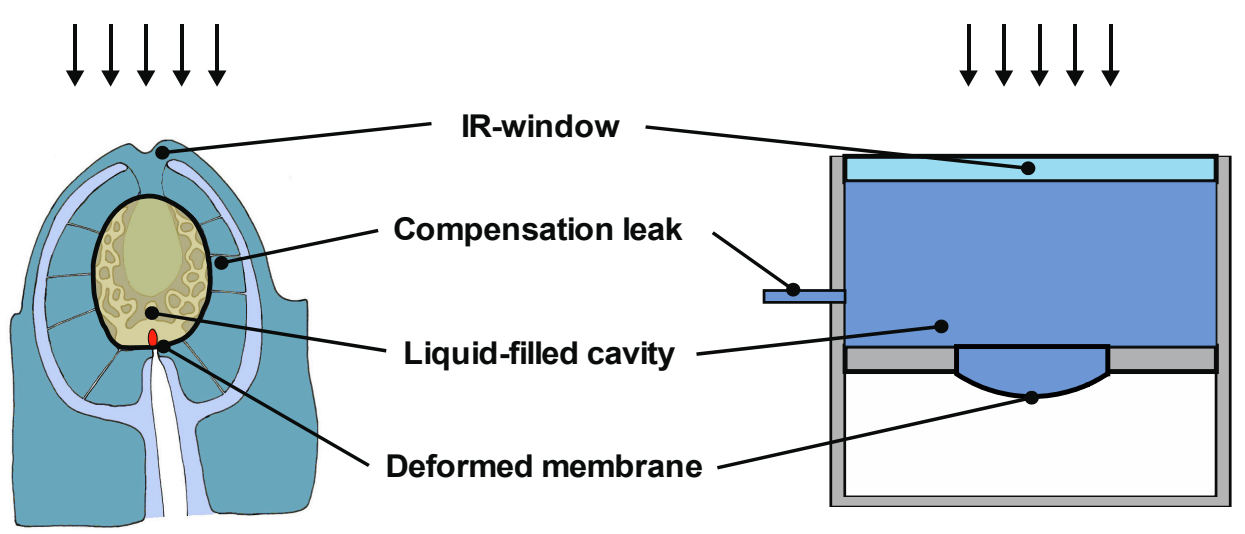

Figure 6. Comparison of the sensillum (left) with the model of the sensor (right).

\subsection{Calculation of the Pressure Increase in the Cavity and the Membrane Deflection}

\subsubsection{Adiabatic Cavity without Compensation Leak}

For calculating the change of the liquid pressure in the cavity based on the temperature profile, the equation of state must be solved. Because the pressure in the cavity depends upon the two independent variables, temperature and volume, its total change is given by:

$$
\Delta P=\beta \cdot \Delta T_{C, \text { mean }}-\frac{1}{\kappa \cdot V} \cdot \Delta V \quad \Delta T_{C, \text { mean }}=\frac{\int_{0}^{H_{C}} T_{C}(z) \cdot d z}{H_{C}}-T_{0}
$$

with $\Delta P$ : pressure increase in the cavity; $\beta=(\partial P / \partial T)_{V}$ : isochoric tension coefficient; $T_{C}(z)$ : temperature increase as a function of the axial coordinate $z$ of the cavity and time; $\Delta T_{C \text {,mean: mean temperature }}$ increase averaged over the cavity; $T_{0}$ : initial (ambient) temperature at $t=0 ; \kappa=-(1 / V) \cdot(\partial V / \partial P)_{T}$ 
isothermal compression coefficient; $V$ : volume of the cavity; and $H_{C}$ : height of the cavity; $\Delta V$ : volume increase. For water $\left(25^{\circ} \mathrm{C}, 1\right.$ bar $) . \beta=5.68 \times 10^{5} \mathrm{~Pa} / \mathrm{K}$ and $\kappa=4.5 \times 10^{-10} \mathrm{~Pa}^{-1}$ [47].

The increase of the volume $\Delta V$ of the cavity results in the tiny deflection of the membrane. For the following calculations, it is assumed that the diameter of the membrane is equal to the diameter of the cavity. The local deflection, $y$, of this membrane caused by a pressure difference can be calculated as a function of the radial distance $r$ with the shell theory $[48,49]$.

$$
\begin{aligned}
& y(r)=\frac{\Delta P}{64 \cdot D} \cdot\left(R^{2}-r^{2}\right)^{2} \\
& D=\frac{E \cdot t_{P}^{3}}{12 \cdot\left(1-v^{2}\right)}
\end{aligned}
$$

with $R$ : radius of the membrane; $D$ : flexural stiffness of the membrane; $E$ : Young's modulus of elasticity; $t_{P}$ : thickness of the membrane; and $v$ : Poisson's ratio.

Equation (7) is a good approximation for small membrane deflections, i.e., $y_{\max } / t_{P}<1$. The corresponding volume change $\Delta V$ can be calculated in relation to the pressure increase $\Delta P$ by Equation (7):

$$
\Delta V=\frac{\pi \cdot R^{6} \cdot \Delta P \cdot\left(1-v^{2}\right)}{16 \cdot E \cdot t_{P}^{3}}
$$

The combination of Equations (7) and (8) yields a relationship for $\Delta P$, which considers the influence of temperature and volume.

$$
\Delta P=\frac{\beta \cdot \Delta T_{C, \text { mean }}}{1+\Omega} \quad \Omega=\frac{R^{4} \cdot\left(1-v^{2}\right)}{16 \cdot E \cdot t_{P}^{3} \cdot H_{C} \cdot \kappa}
$$

The factor $\Omega$ characterizes the change of state of the liquid inside the cavity due to a temperature increase: For $\Omega \rightarrow 0$, which corresponds to an extremely hard membrane, the change of state is isochoric with a maximal pressure increase and minimal membrane deflection. For $\Omega \rightarrow \infty$, as for an extremely soft membrane, the change of state is isobaric with maximal volume increase and maximal membrane deflection. The transition between these two cases is at $\Omega \approx 1$. The maximal deflection, $y_{\max }$, at $r=0$ of the circular membrane can be calculated as a function of the factor $\Omega$ by using Equations (7) and (9).

$$
y_{\max }=\frac{3 \cdot \alpha \cdot \Omega \cdot \Delta T_{C, \text { mean }} \cdot H_{C}}{1+\Omega}
$$

where, $\alpha=\beta \cdot \kappa$ is the isobaric thermal expansion coefficient.

Figure 7 shows the maximal deflection as a function of the factor $\Omega$ according to Equation (10) for an IR power density of $10 \mathrm{~W} / \mathrm{m}^{2}$ (IR-window without absorption loss assumed) for a cavity with a height and a diameter of $0.5 \mathrm{~mm}$, respectively, filled with water. Obviously, the maximal deflection is achieved for the isobaric case with a very soft membrane.

With regard to Equations (9) and (10), the maximal deflection of the membrane can be increased by using a liquid with a high thermal expansion coefficient, $\alpha$, and a high mean temperature increase,

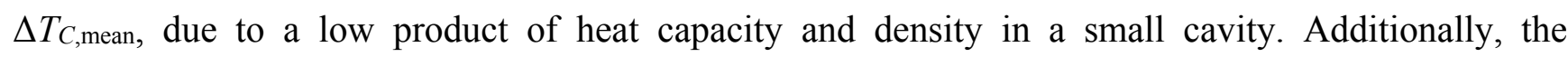
IR-window and the cavity material should have a low heat conduction to avoid heat losses during the measurement (see Section 4.3). 


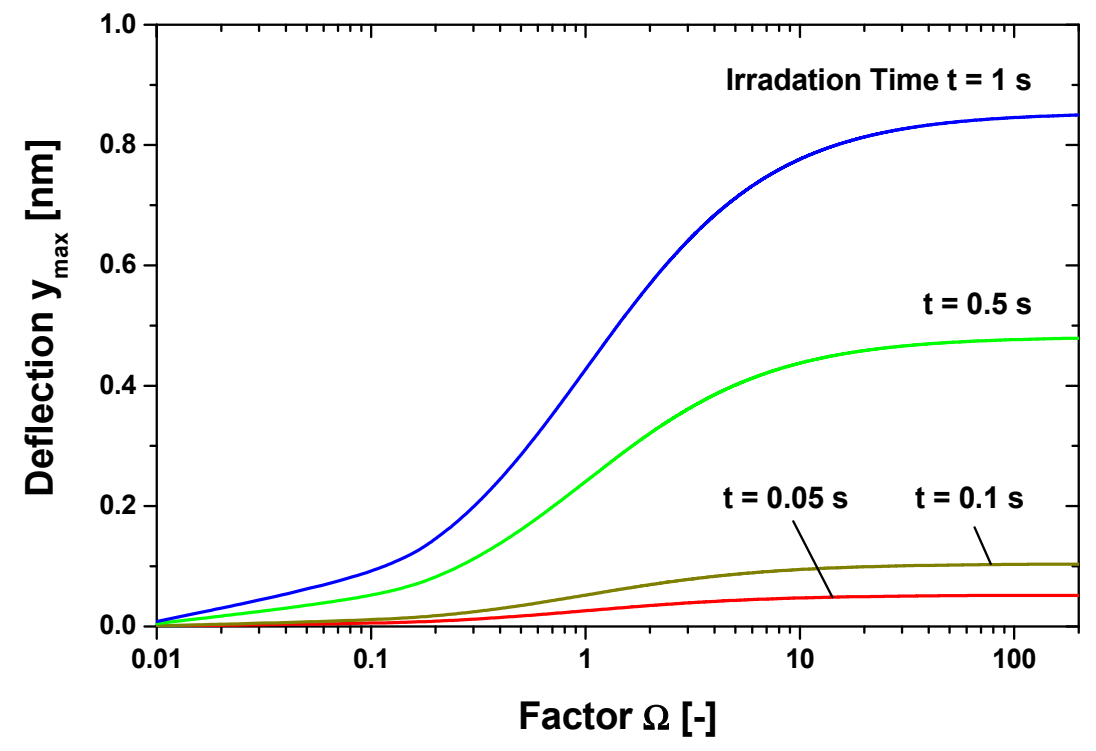

Figure 7. Maximum central deflection, $y_{\max }$, at $r=0$ of a circular membrane (silicon, $1 \mu \mathrm{m}$ thickness) as function of factor $\Omega$ and irradiation time for a water-filled cavity. IR power density: $10 \mathrm{~W} / \mathrm{m}^{2}$, diameter and height of the cavity: $0.5 \mathrm{~mm}$.

\subsubsection{Non-Adiabatic Cavity with Compensation Leak}

In the Melanophila IR receptor, the inner sphere is enclosed by a thin layer of fluid, which is always at ambient pressure. Therefore the nanocanals in the shell of the sphere allow the exchange of fluid in and out of the microfluidic compartment in the sphere (see Figure 8, left). Thus any internal pressure change that may be caused by the slowly changing ambient temperature can be compensated. Golay sensors also use such compensation leaks for compensating changes of ambient temperatures [44].

However, due to the compensation leak, the pressure increase in the cavity is reduced depending on the flow resistance of the leakage through the canal. For simulating this effect, an analysis based on the model in Figure 8, right, was carried out. A mass and energy balance for the sub-systems cavity, canal and reservoir can be used to derive the formulas for the time-dependent development of temperature and pressure in the cavity. For a laminar flow in the canal, a uniformly distributed absorption of the IR power in the cavity, an adiabatic top and bottom of the cavity and a constant wall temperature system of two differential equations can be derived [50].

$$
\begin{array}{cc}
\left(1+\Omega+\frac{\alpha \cdot \Omega}{\rho_{C} \cdot c_{p}} \cdot P_{C}\right) \cdot \frac{d P_{C}}{d t}+\frac{P_{C}}{\tau_{C}}-\frac{P_{R}}{\tau_{C}}=\gamma \cdot e^{-t / \Theta} \\
\frac{d P_{R}}{d t}+\frac{P_{R}}{\tau_{R}}-\frac{P_{C}}{\tau_{R}}=0 & \tau_{R}=\frac{8 \cdot \eta \cdot L \cdot V_{R} \cdot \kappa}{\pi \cdot R_{L}^{4}} \\
\tau_{C}=\frac{8 \cdot \eta \cdot L \cdot V_{C} \cdot \kappa}{\pi \cdot R_{L}^{4}} & \gamma=\frac{\beta \cdot I_{0}}{\rho \cdot c_{p} \cdot H_{C}}
\end{array}
$$

with $V_{C}, P_{C}$ : volume and pressure in the cavity, respectively; $V_{R}, P_{R}$ : volume and pressure in the reservoir, respectively; $\rho, c_{p}, \eta, \lambda$ : density, heat capacity, dynamic viscosity and heat conductivity of 
the fluid in the cavity, respectively; $\tau_{C}, \tau_{R}$ : time constants of cavity and reservoir, respectively; $R_{L}$ : radius of canal; $L$ : length of canal; and $I_{0}$ : IR power density.

For $\Theta \rightarrow \infty$, that means an adiabatic cavity with no heat conduction into the wall, the differential Equation (11) changes into the solution for an adiabatic cavity. Figure 9 shows the time-dependent pressures in the cavity and the reservoir according to Equation (11) with variable heat loss of the cavity (decreasing value of $\Theta$ corresponding to increasing heat loss). Compared to the adiabatic cavity $(\Theta \rightarrow \infty)$, the pressures reach a stable state where the difference of the pressure in the cavity and the reservoir is zero (Figure 10). Increasing the heat loss of the cavity reduces the pressure in the cavity at a given time considerably. In case of a low flow resistance of the canal (small values of time constant $\tau_{C}$ and $\left.\tau_{R}\right)$ and a high heat loss, the pressure difference between cavity and reservoir reduces to a short pressure pulse. Figure 11 shows the influence of the heat loss of the cavity and a reservoir volume of $100 \times$ cavity volume on the maximal deflection.
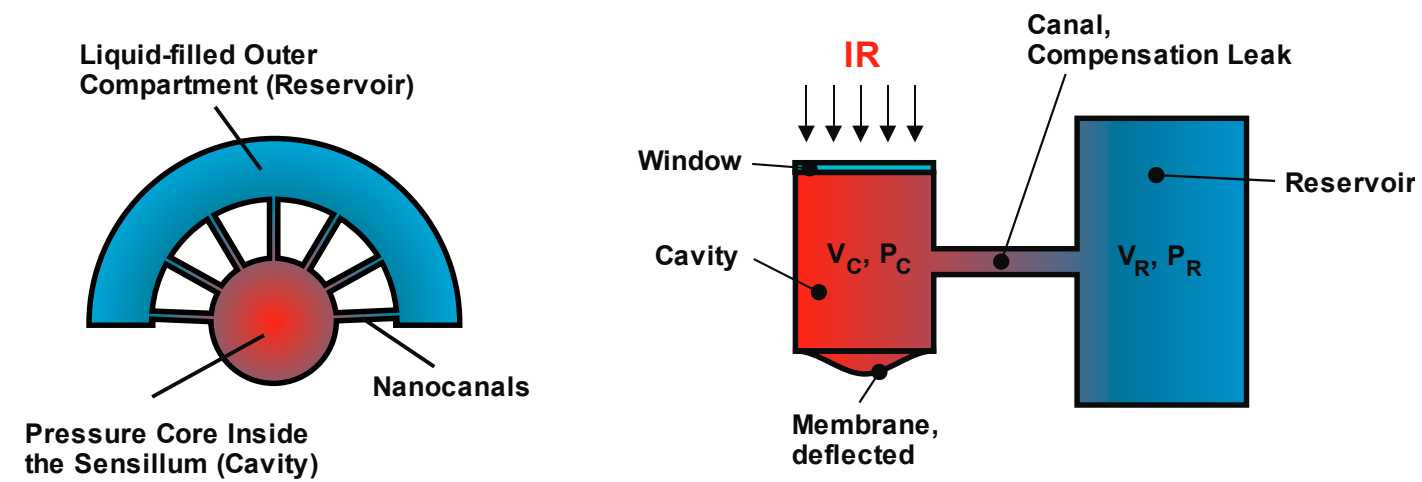

Figure 8. Model of the sensillum with nanocanals (left) and Model of the IR sensor (right) with cavity (pressure $P_{C}$, volume $V_{C}$ ) and reservoir (pressure $P_{R}$, volume $V_{R}$ ). The canal of the compensation leak has a radius $R_{L}$ and a length $L$.

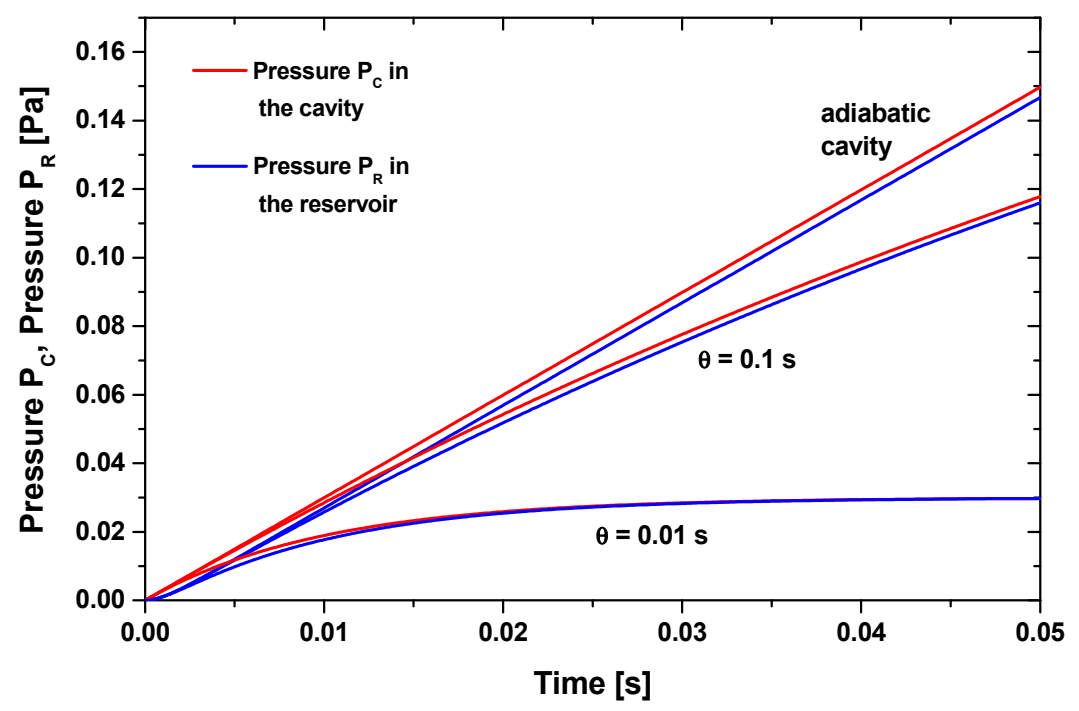

Figure 9. Time dependent pressure in the non-adiabatic cavity and the reservoir as a function of the heat loss from the cavity (decreasing value of $\Theta$ corresponding to increasing heat loss and $\Omega=1000, \gamma=3000\left(I_{\mathrm{o}}=10 \mathrm{~W} / \mathrm{m}^{2}\right), \tau=0.001 \mathrm{~s}$ for equal size of cavity $V_{C}$ and reservoir $V_{R}$. 


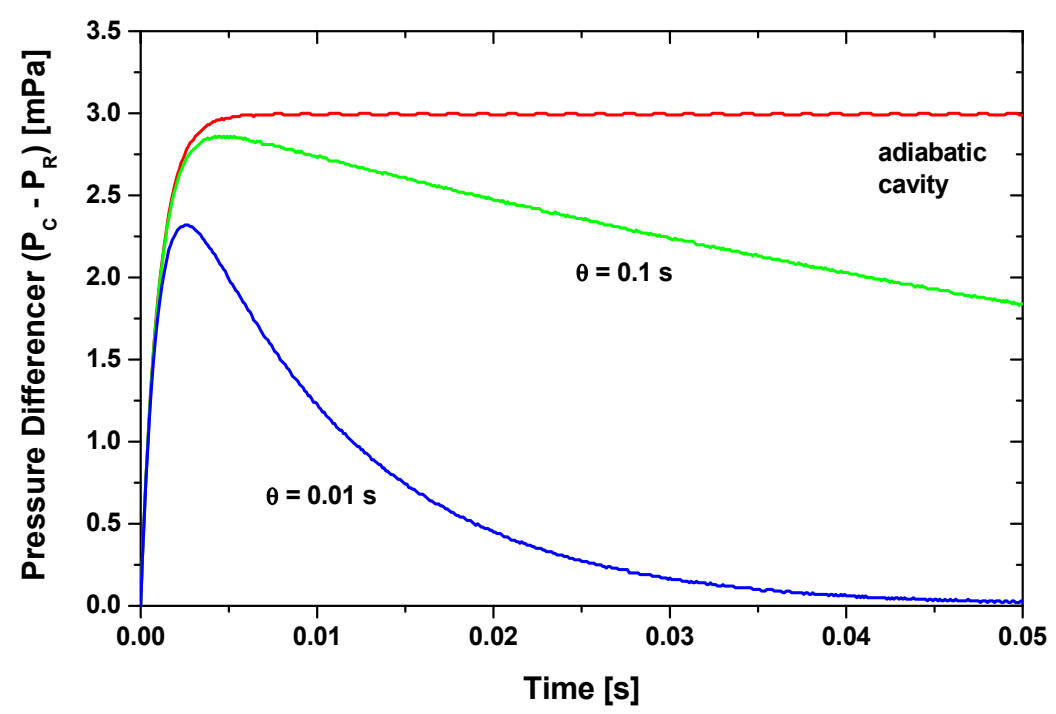

Figure 10. Time-dependent pressure difference between the non-adiabatic cavity and the reservoir as a function of the heat loss from the cavity and $\Omega=1000, \gamma=3000\left(I_{0}=10 \mathrm{~W} / \mathrm{m}^{2}\right)$, $\tau_{C}=\tau_{R}=0.001 \mathrm{~s}$ for equal size of cavity $V_{C}$ and reservoir $V_{R}$.

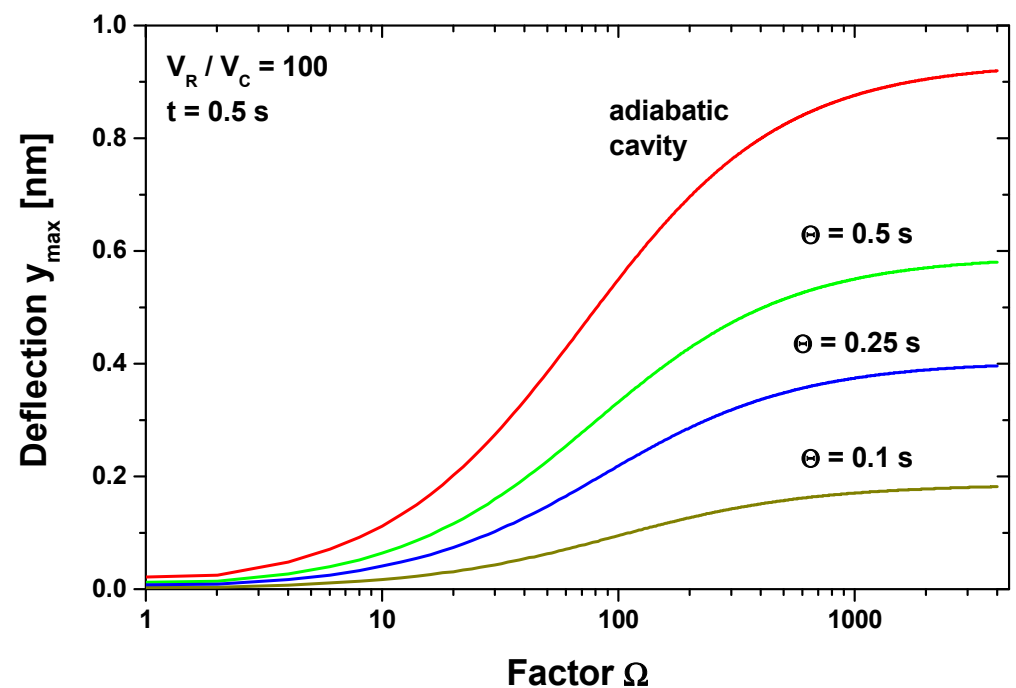

Figure 11. Maximum central deflection, $y_{\max }$, of a circular membrane (silicon, $1 \mu \mathrm{m}$ thickness) as a function of the factor $\Omega$ and heat loss time constant $\Theta$ for a water-filled cavity. IR power density: $10 \mathrm{~W} / \mathrm{m}^{2}$, irradiation time: $0.5 \mathrm{~s}$, diameter and height of the cavity: $0.5 \mathrm{~mm}$, Volume reservoir: $100 \times$ volume of cavity.

It is obvious that a non-adiabatic cavity reduces significantly the membrane deflection. The influence of an increasing reservoir volume on the membrane deflection is shown in Figure 12, assuming a constant heat loss. A larger reservoir volume shifts the deflection curve towards higher $\Omega$ values; that means that a hard membrane results in a significantly lower deflection, whereas the deflection of a soft membrane is only marginally influenced. 


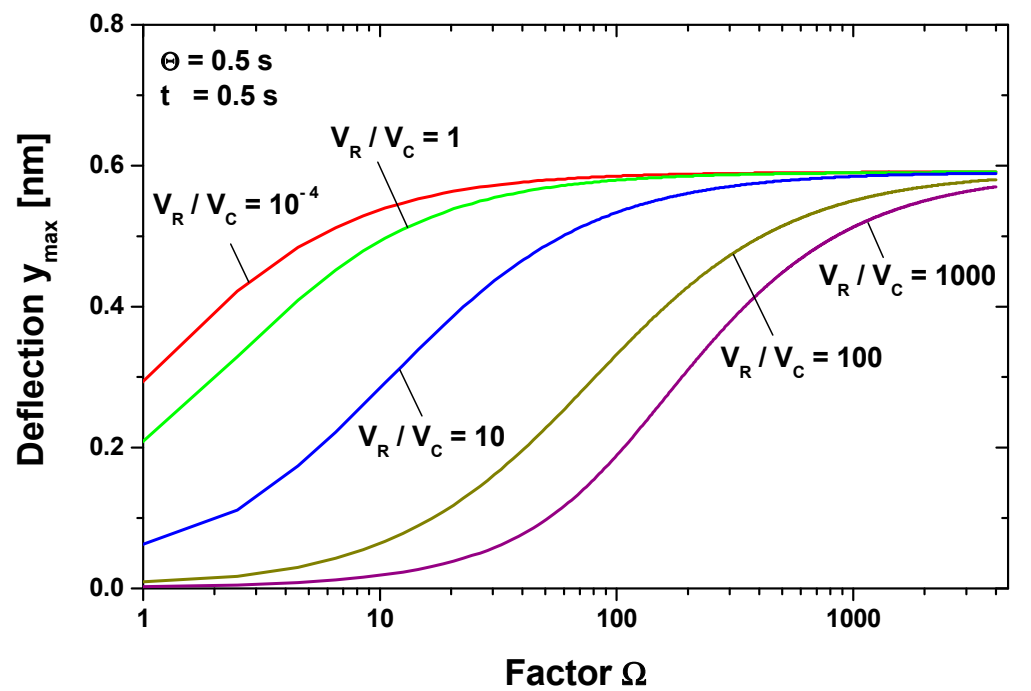

Figure 12. Maximum central deflection, $y_{\max }$, of a circular membrane (silicon, $1 \mu \mathrm{m}$ thickness) as function of factor $\Omega$ and the relation of cavity volume to reservoir volume for a water-filled cavity. IR power density: $10 \mathrm{~W} / \mathrm{m}^{2}$, irradiation time: $0.5 \mathrm{~s}$, diameter and height of the cavity: $0.5 \mathrm{~mm}$, heat loss time constant $\Theta: 0.5 \mathrm{~s}$.

\subsubsection{Influence of Membrane Stress on the Membrane Deflection}

The equations presented here are true for small membrane deflections in relation to the membrane thickness, $y_{\max } / t_{P}<1$. However, $y_{\max } / t_{P}>1$ results in a non-linear relation between the membrane deflection and the pressure difference because the membrane stress cannot be neglected as in the linear case. In [51], an implicit equation for the non-linear case is given, applicable for $y_{\max } / t_{P}>1$ :

$$
\begin{aligned}
& \frac{y_{\max }}{t_{P}}=\frac{\Delta P}{64 \cdot D \cdot t_{P}} \cdot \frac{R^{4}}{1+0.488 \cdot\left(\frac{y_{\max }}{t_{P}}\right)^{2}} \\
& \text { with } D=\frac{E \cdot t_{P}^{3}}{12 \cdot\left(1-v^{2}\right)}
\end{aligned}
$$

the flexural stiffness of the membrane.

For $y_{\max } / t_{P} \rightarrow 0$, Equation (12) changes over to the linear case in Equation (7). Figure 13 shows the relative deflection, $y_{\max } / t_{P}$, for the non-linear and the linear case. A high pressure bias due to an ambient temperature change will reduce the sensor characteristic $\Delta y / \Delta P$ in the new operating point compared to an operating point without ambient temperature change, that means $\Delta P=0$ in Figure 13. This leads to a lower deflection at a new operating point as a result of the absorbed IR radiation and a sensor operation dependent on the ambient temperature.

Here a compensation leak acts like a reset for the membrane deflection. The non-linearity is also influenced by the fluid in the cavity because the pressure difference, $\Delta P$, in Equation (6) depends on the mean temperature increase of the fluid, which changes with regard to the material values of the fluid (see Section 4.3). 


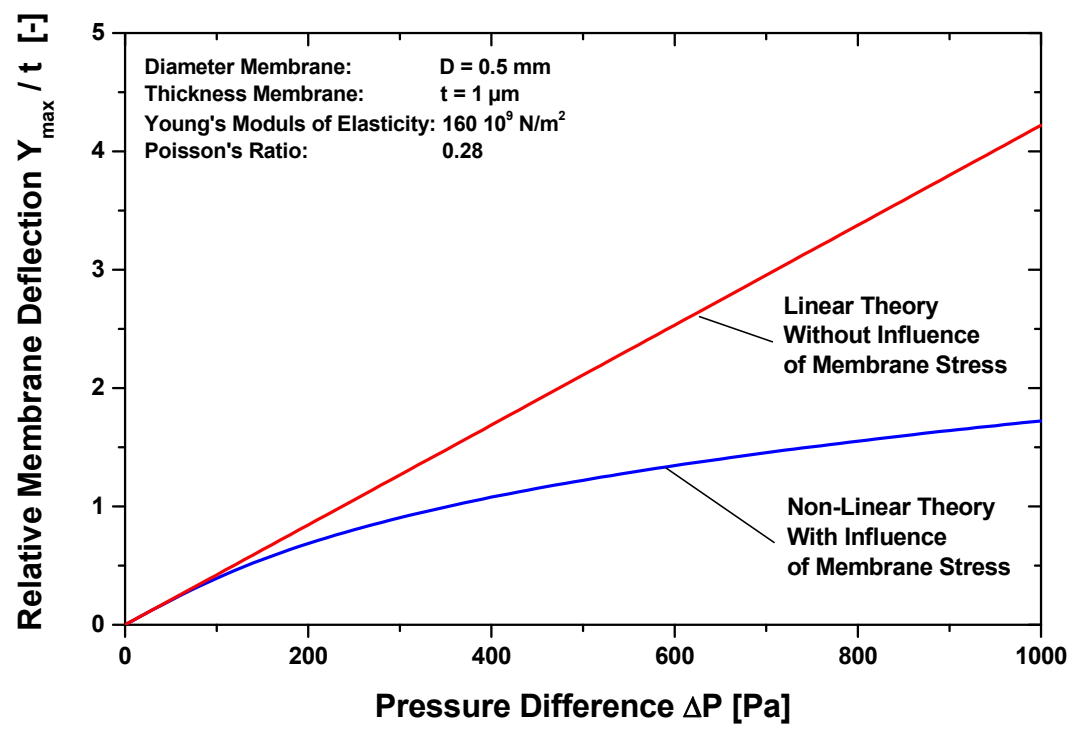

Figure 13. Relative plate deflection at $r=0$ as a function of applied pressure difference compared the influence of a membrane stress for a water-filled cavity.

\subsection{Evaluation of Sensor Components}

\subsubsection{Cavity Material}

The deflection of the membrane is a measure for the IR-radiation that is to be determined. For this reason the design parameters for an optimal large deflection should be identified. Obviously a high mean temperature should be achieved in the fluid. This means, that the IR-window should be very low and the fluid have very high IR absorption. A high mean temperature difference due to the absorbed energy depends in principle on two effects based on the first law of thermodynamics: an almost adiabatic cavity to minimize the heat losses and a fluid with a low product of density and heat capacity.

The thermal effusivity, $b$, characterizes the transient behavior of the contact temperature between two different materials.

$$
b=\sqrt{\lambda \cdot \rho \cdot c_{p}}
$$

with $\lambda$ : heat conductivity; $\rho$ : density; and $c_{p}$ : heat capacity (all for the materials of the cavity).

Comparing two surfaces of the same initial temperature, the surface with a high thermal effusivity, e.g., steel, feels cold to the touch, whereas the surface with a low thermal effusivity, e.g., wood, feels warm. Therefore the thermal effusivity can be a measure of a material regarding the ability of thermal insulation. Here the absorbed energy in the cavity should be reduced only slightly due to heat conduction in the cavity wall; thus, a cavity material with a low thermal effusivity is preferred. Figure 14 compares the thermal effusivity for different cavity materials and insect cuticle. It is obvious that only plastics reach the same good isolation abilities as cuticles. Silicon, with regard to heat isolation, is considered a disadvantageous solution; glass would offer a thermal effusivity. which is one order of magnitude better. Furthermore, the manufacturing technology must be kept in mind. The production of small structures from silicon in clean rooms is well known and the manufacturing of the membrane can be included. Small plastic structures can be manufactured by micro-injection molding, which is also state of the art. 


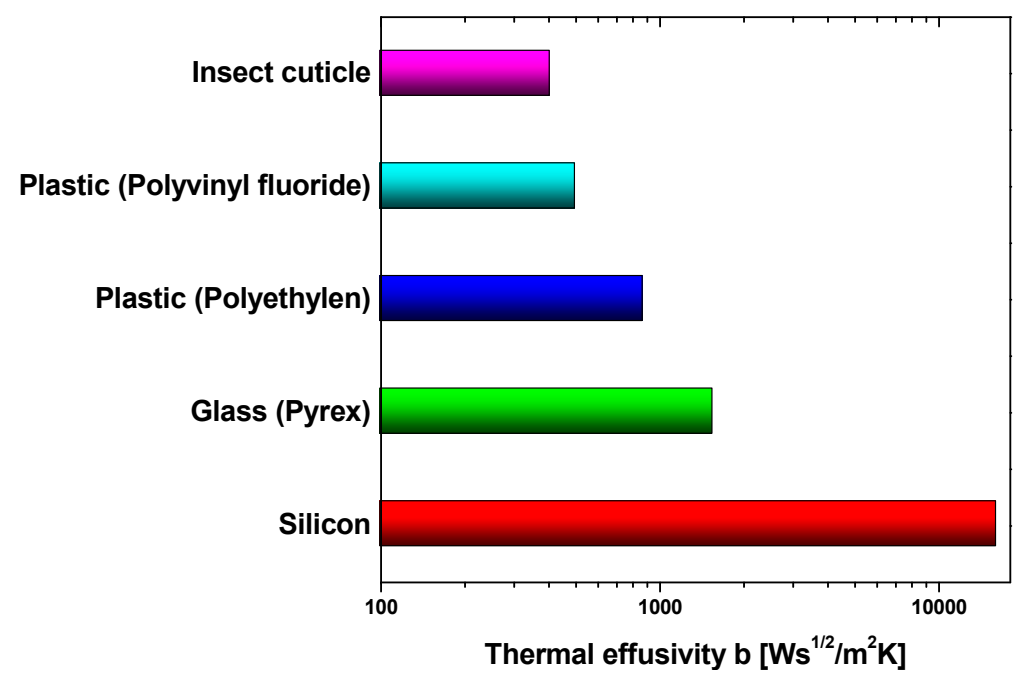

Figure 14. Comparison of the thermal effusivity, $b$, for different materials (Polyvinyl fluoride under the trade name Tedlar $^{\circledR}$ is a registered trademark of DuPont; Pyrex ${ }^{\circledR}$ is a registered trademark of Corning Incorporated).

\subsubsection{Window Material}

A critical component is also the IR-window. This should have a very low IR-absorption coefficient and a low heat conductivity to prevent heat loss from the cavity, especially when the fluid has a high absorption coefficient. In this case, the radiation is absorbed in a very thin zone directly behind the IR-window, which implies an increased heat loss through the window. Unfortunately an optimal material for the IR-window sealing the fluid-filled cell is not known: conventional IR-materials like chalcogenide glasses, Ge, Si, ZnS, or ZnSe have low absorption coefficients, but show relatively high heat conductivities, whereas plastic has a low heat conduction, but a high absorption coefficient. In $[51,52]$, the temperature distribution based on different window material and fluids with different absorption coefficients are compared. It turns out that in the case of an IR window made of plastic $\left(\right.$ Tedlar $\left.^{\circledR}\right)$, the window should only have a thickness of about $100 \mu \mathrm{m}$ for an equal heat loss to a glass window of $0.5 \mathrm{~mm}$ thickness, which would lead to significant problems with manufacturing and stability. Due to the lower IR-absorption coefficient of the hydrocarbons compared to water, the absorption zone becomes broader and the temperature maximum is not directly behind the window. This also reduces the heat loss through the window and allows adjusting the depth of the cavity. The thickness of the zone where the whole IR-radiation is absorbed can serve as a specification for the cavity depth; a larger cavity depth will only reduce the mean temperature due to the larger fluid volume.

\subsubsection{Liquid as Cavity Filling}

The thermo-physical properties of the fluid are responsible for the effective conversion of the temperature increase of the fluid into a large deflection of the membrane. For an adiabatic cavity, an equation can be derived which relates the maximum membrane deflection and the properties of the fluid for a constant absorbed energy in the fluid.

$$
\frac{y_{\max }}{I_{0}}=\frac{\Omega}{1+\Omega} \cdot \frac{3 \cdot \alpha}{\rho \cdot c_{p}} \cdot t=\delta \cdot t
$$


with $I_{0}$ : IR power density; and $\delta$ : relative deflection of the membrane.

The relative deflection $\delta$ from Equation (14) is defined as the maximum deflection of the membrane, divided by an absorbed energy of $1 \mathrm{~J} / \mathrm{m}^{2}$ (cross-section of the cavity) in the fluid. For cavities with the same cross-section, the influence of the fluid and the properties of the membrane can be compared. Figure 15 shows for a soft membrane (isobaric case, $\Omega>>1$, for the definition of $\Omega$ see Equation (9)) the relative deflection for different fluids. It turns out that hydrocarbons would cause a deflection that is one order of magnitude larger compared to water. However, fluids like carbon tetra chloride or diethylether have some serious drawbacks like low evaporation temperature, incompatibility with other materials or toxicity. Although pentane or toluene are used in precision thermometers due to their high isobaric thermal expansion coefficient, the use in the cavity is problematic because of the too complicated filling procedure of the cavity, which must be absolutely bubble free. Additionally, some hydrocarbons can damage plastics, such as the cavity material and adhesives, e.g., used to connect the IR-window with the cavity. Another evaluation criterion is the IR absorption of the liquid filling. Water has a high IR absorption, hydrocarbons have a significantly lower absorption, by a factor $10^{-1}$ to $10^{-2}$ (see Table 4). A high absorption causes a thin absorption zone directly behind the window and an energy loss due to the heat conduction through the window. The lower absorption of hydrocarbons shift the temperature maximum more towards the middle of the cavity with lower heat loss through the window (see Figure 15).

Methanol or ethanol may be a compromise as a liquid cavity filling regarding advantages and disadvantages, however, the compatibility with the sensor material and glues must be investigated carefully.

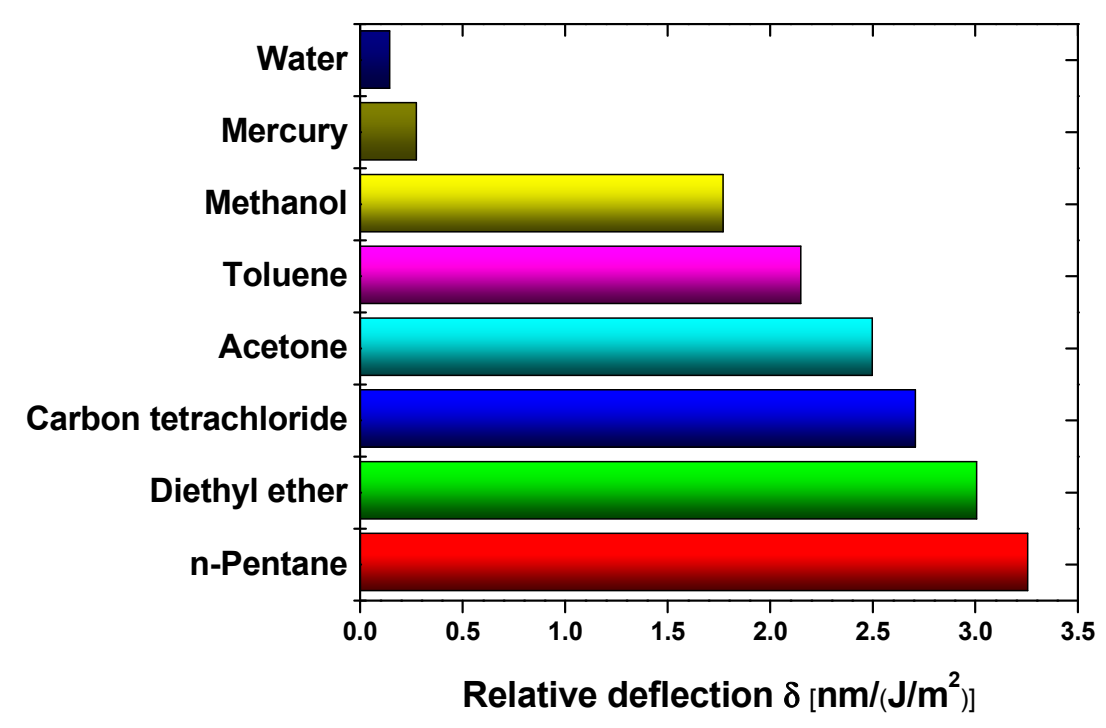

Figure 15. Comparison of the relative deflection $\delta$ of the membrane for different fluids (isobaric case, $\Omega>>1$, see Equation (9)). For the same cross section of the cavity, the relative deflection is caused by the same amount of energy absorbed in the fluids. The dimensions and the material properties of the according membrane can be calculated with $\Omega$, see Equation (9) for $\Omega>>1$. 
Table 4. Comparison of IR absorption coefficients in the bandwidth 3-5 $\mu \mathrm{m}$ using data from [53].

\begin{tabular}{cc}
\hline Compound & Absorption Coefficient $\left(\mathbf{c m}^{-\mathbf{1}}\right)$ \\
\hline Water & 1140 \\
n-Pentane & 73 \\
Toluene & 94 \\
Methanol & 7 \\
\hline
\end{tabular}

\subsubsection{Gas as Cavity Filling}

Using gas instead of water in the cavity as in the well-known pneumatic Golay sensors yields different results due to the different material properties, in particular density $\rho$, heat capacity $c_{p}$, and the coefficients $\beta, \kappa$, and $\alpha$ in Equations (6) and (10). For a better comparison with the water-filled cavity, it is assumed that also a thin zone, due to a thin absorbing film on the inner glass surface, exists. There all the radiation is absorbed and this energy heats up the gas by heat conduction. The resulting temperature profile for water and gas $0.5 \mathrm{~s}$ after the onset of IR irradiation is shown in Figure 16, based on the same IR power density of $10 \mathrm{~W} / \mathrm{m}^{2}$. Mainly due to the lower product of density and heat capacity, the temperature increase in the gas is higher; the mean temperature increase $\Delta T_{\text {mean }}$ is in the case of water $1.2 \mathrm{mK}$ and $4.8 \mathrm{mK}$ in the case of gas. Using Equation (9), this causes, e.g., for $\Omega=1$, a pressure difference, $\Delta P$, of $350 \mathrm{~Pa}$ in the case of water, but only $0.8 \mathrm{~Pa}$ in the case of gas. However, the maximal deflection of the membrane in the case of gas is $12 \mathrm{~nm}$ compared to $0.2 \mathrm{~nm}$ in the case of water (see Figure 17). This surprising fact can be explained by the higher mean temperature increase and by the higher thermal expansion coefficient in the case of gas compared to water. The maximal deflection of the membrane is about $2 \mathrm{~nm}$ compared to about $1 \mathrm{~nm}$ in the case of hydrocarbons (Table 5).

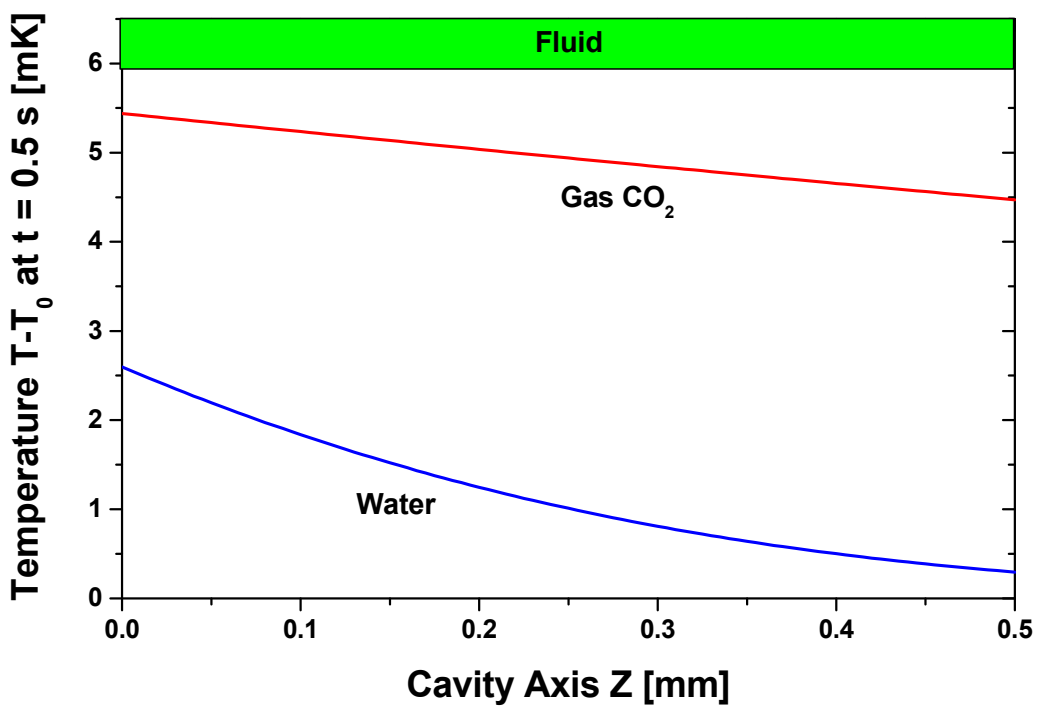

Figure 16. Temperature distribution along the cavity axis $0.5 \mathrm{~s}$ after the onset of irradiation for a water-filled and a $\mathrm{CO}_{2}$-filled cavity with an IR power density at the outer window surface of $10 \mathrm{~W} / \mathrm{m}^{2}$. In the case of gas, a thin IR absorber film is assumed on the inner glass surface where all the IR energy is absorbed. 


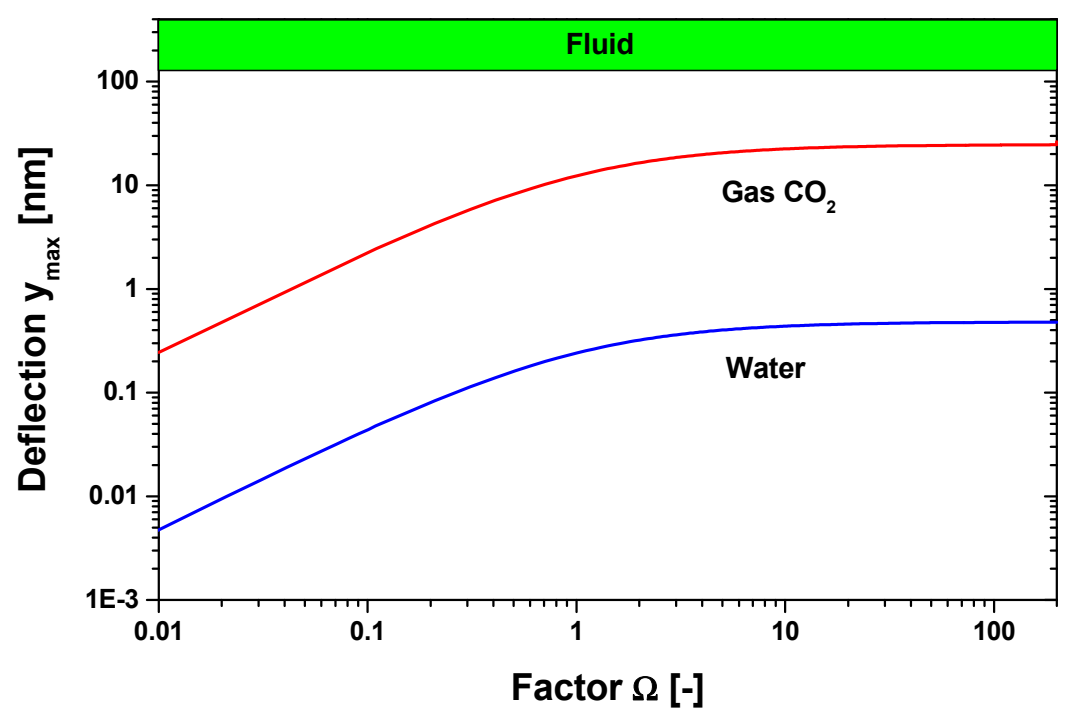

Figure 17. Maximum central deflection, $y_{\max }$, of a circular membrane at $t=0.5 \mathrm{~s}$ as function of factor $\Omega$ for a water-filled and $\mathrm{CO}_{2}$-filled cavity. IR power density of $10 \mathrm{~W} / \mathrm{m}^{2}$, diameter and height of the cavity: $0.5 \mathrm{~mm}$.

Table 5. Comparison of the mean temperature increase $\Delta T_{\text {mean, }}$ the factor $\Omega$ and the maximum deflection of $y_{\max }$ of the membrane due to different liquids and $\mathrm{CO}_{2}$ gas after $50 \mathrm{~ms}$ irradiation of $10 \mathrm{~W} / \mathrm{m}^{2}$.

\begin{tabular}{cccc}
\hline Compound & $\boldsymbol{\Delta} \boldsymbol{T}_{\text {mean }}(\mathbf{m K})$ & $\boldsymbol{\Omega}$ & $\boldsymbol{y}_{\max }(\mathbf{n m})$ \\
\hline Water & 0.14 & 6245 & 0.04 \\
n-Pentane & 0.53 & 1126 & 1.26 \\
Toluene & 0.64 & 3093 & 1.03 \\
$\mathrm{CO}_{2}$, Gas & 1.57 & 0.281 & 2.18 \\
\hline
\end{tabular}

Using different gases will not change the result notably because only the individual gas constant and the heat capacity are variable. However, using a gas with low heat conductivity like Argon or Xenon will reduce the radial heat losses into the cavity wall and yield a higher temperature increase. Figure 18 shows the temperature profile in the window and the cavity using different liquids and gas as filling. Here, in the case of gas, a thin absorption zone at the inner window surface was used. Despite the unfavorable position of the absorption zone, the temperature profile is more homogeneous compared to water and the mean temperature is increased. A homogeneously distributed absorber in the cavity would be a good solution resulting in reduced heat loss through the window and improved membrane deflection. This can be achieved using a thin opaque plastic mesh with a high surface for heat transmission and a low heat capacity. 


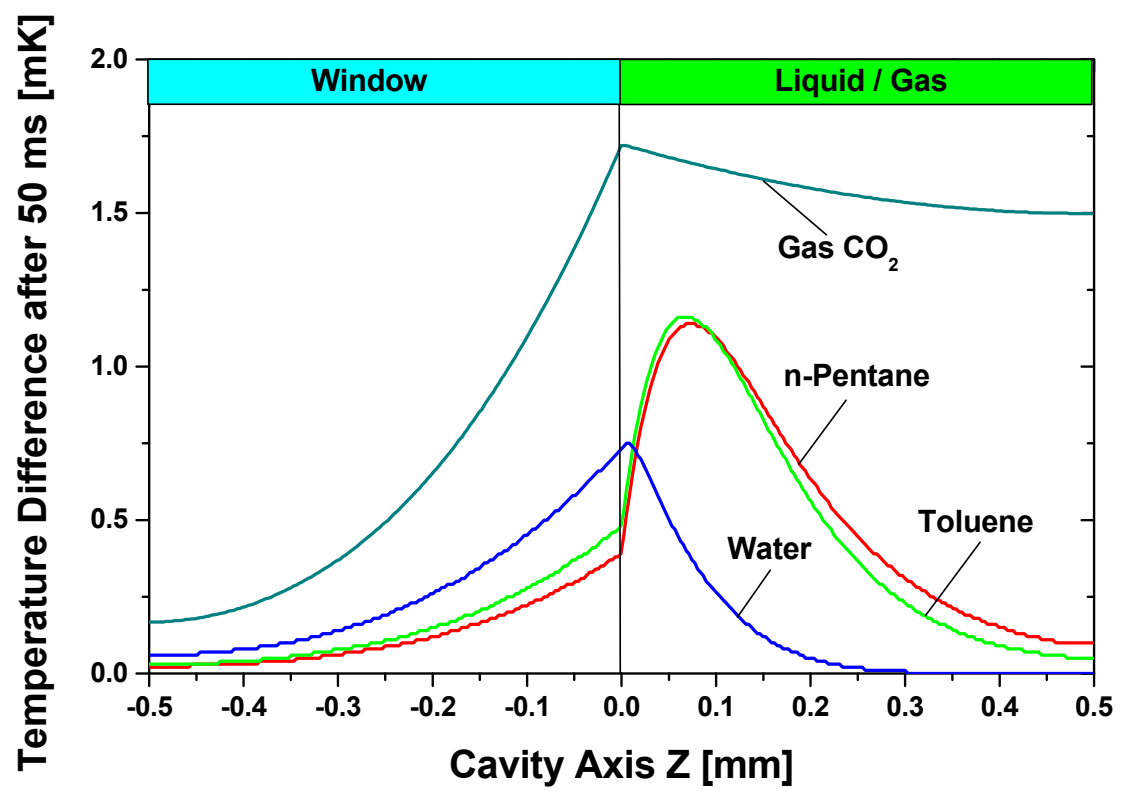

Figure 18. Temperature distribution along the cavity axis $0.5 \mathrm{~s}$ after the onset of irradiation for different liquids with an IR power density at the outer window surface of $10 \mathrm{~W} / \mathrm{m}^{2}$. For gas an absorption zone at the inner window surface is assumed.

\subsubsection{Read-Out of the Membrane Deflection}

The calculated deformation of the membrane in the case of water as liquid and the deformation of the tip of the dendrite in the sensillum have the same magnitude. In mechanoreceptors like the sensillum deformations of the tip of the dendrite of only $0.1 \mathrm{~nm}$ - corresponding to an energy of $10^{-19} \mathrm{~J}$-yield a receptor potential. As a consequence of the tiny deformation of the membrane, the technical sensor needs a read-out system that is able to detect deformations in the nm-range, such as interferometry, tunneling contacts [46], a capacitive position sensor with nanometer resolution [54] or a capacitance. However, the manufacturing of a thin membrane and a capacitor with very low plate distance to read out the tiny deflections is very difficult. Therefore the usage of tunneling contacts seems to be the best solution [55].

\subsubsection{Final Recommendation for the Design of the Sensor}

Like the biological model, the technical sensor should exhibit its maximal sensitivity in the range of 2-5 $\mu \mathrm{m}$ corresponding to the maximum of emission of a forest fire. The sensillum of the beetle uses a liquid as filling of the cavity because the mechanosensory dendrite as read-out needs a liquid environment. However, the evaluation of the biomimetic sensor showed that a liquid as filling has a lot disadvantages in comparison with a gas filling as in regular Golay Sensors: the material properties of the liquids results always in smaller membrane deflections compared to gas, the bubble-free filling of a micro-cavity is still an unsolved problem, plastic as cavity material and hydrocarbons as filling are problematic regarding the chemical compatibility of the cavity material and glues. The only advantage of a liquid is that no additional IR-absorber has to be used, as in the case of gas. For the cavity material, silicon is disadvantageous because of the high heat conduction of silicon causing a high heat loss. Using plastic as cavity material by applying micro-injection molding as the manufacturing 
technology seems to be the best solution. The best read-out system, capacitive or tunneling contacts, depends on the selected materials and the manufacturing technology. This is in any case a very important topic because the read-out system defines the sensitivity of the system.

\section{Discussion: Bioinspired Improvements of Fire-Detecting UAVs}

Actually, the application of unmanned autonomous flying objects, or Unmanned Aerial Vehicles (UAVs), for forest fire detection has been evaluated for more than 15 years [6,56-60]. The location and identification of artificial fires at known locations could be demonstrated. However, reports about the detection of unpredictable natural fires are not available. A major problem still is the unambiguous classification of an unknown smoke and/or heat source as forest fire. Confusions may easily arise, especially from deep-hanging cloud banks, but also from smoke and heat emitted from various industrial production processes. This problem increases with increasing distance to the respective source.

Regardless of the many advantages (e.g., lower costs than manned aircrafts), current UAV approaches have some drawbacks: (i) the continuous flying is power consumptive; (ii) in the worst case, a fire starts when the drone scans a different part of its monitoring area; and (iii) depending on the sensors on board of the drone (e.g., a video camera), the error probability is still high, meaning that the drone finally has to approach the source for clear identification or the potential fire even has to be inspected by other devices, which all costs additional time.

Given that some prerequisites are fulfilled, an artificial "fire beetle", tentatively called beetlecopter, can overcome these problems. As already mentioned, it is unlikely that a Melanophila beetle permanently flies over large areas in search for a fire. This behavior would not increase the chance for detecting a fire because the locality where a fire may start is unpredictable and definitively would cost the small beetle too much energy. Instead, the beetle most probably performs short search flights lasting for only a few minutes. Depending on the weather conditions, search flights can be made once a day or every hour. During a search flight, at an appropriate height, the beetle flies in a circle looking out for a smoke plume characterized by a basal zone of IR emission (Figure 19A). Therefore our concept of the beetlecopter, for instance based on a commercial drone like a quadrocopter, comprises the following basics:

1. The drone is equipped with a high-resolution video camera and a highly sensitive image forming IR sensor.

2. At adjustable times, the drone ascends from a base station to a preset height and - by turning through $360^{\circ}$ - scans its surrounding area ( 1 or 2 min per search flight). Afterwards, the drone lands on its base station.

3. If a fire is detected, an alarm is send to an earth station.

4. Several drones can be used to establish a "beetlecopter" network suitable to monitor a large area (Figure 19B).

The dual sensors looking at different regions of the electromagnetic spectrum (VIS, IR) will reduce the error probability to virtually zero. An alarm is released only if a zone of extra IR emission is detected at the base of the potential smoke plume (Figure 19A). This allows a reliable discrimination between a smoke plume and a deep-hanging cloud bank. Previous studies have already shown that the 
combination of a visual and an IR camera helps to reduce false alarms [61]. It has to be pointed out, however, that the usability of the proposed beetlecopter system strongly depends on the sensitivity of the IR sensor.

For the effective implementation of the beetlecopter concept, a biomimetic photomechanic IR sensor based on the Melanophila sensilla should be used. Because those sensors are currently unavailable, in the beginning, commercially available uncooled bolometer IR sensors could be used. However, this will not allow a huge detection range.
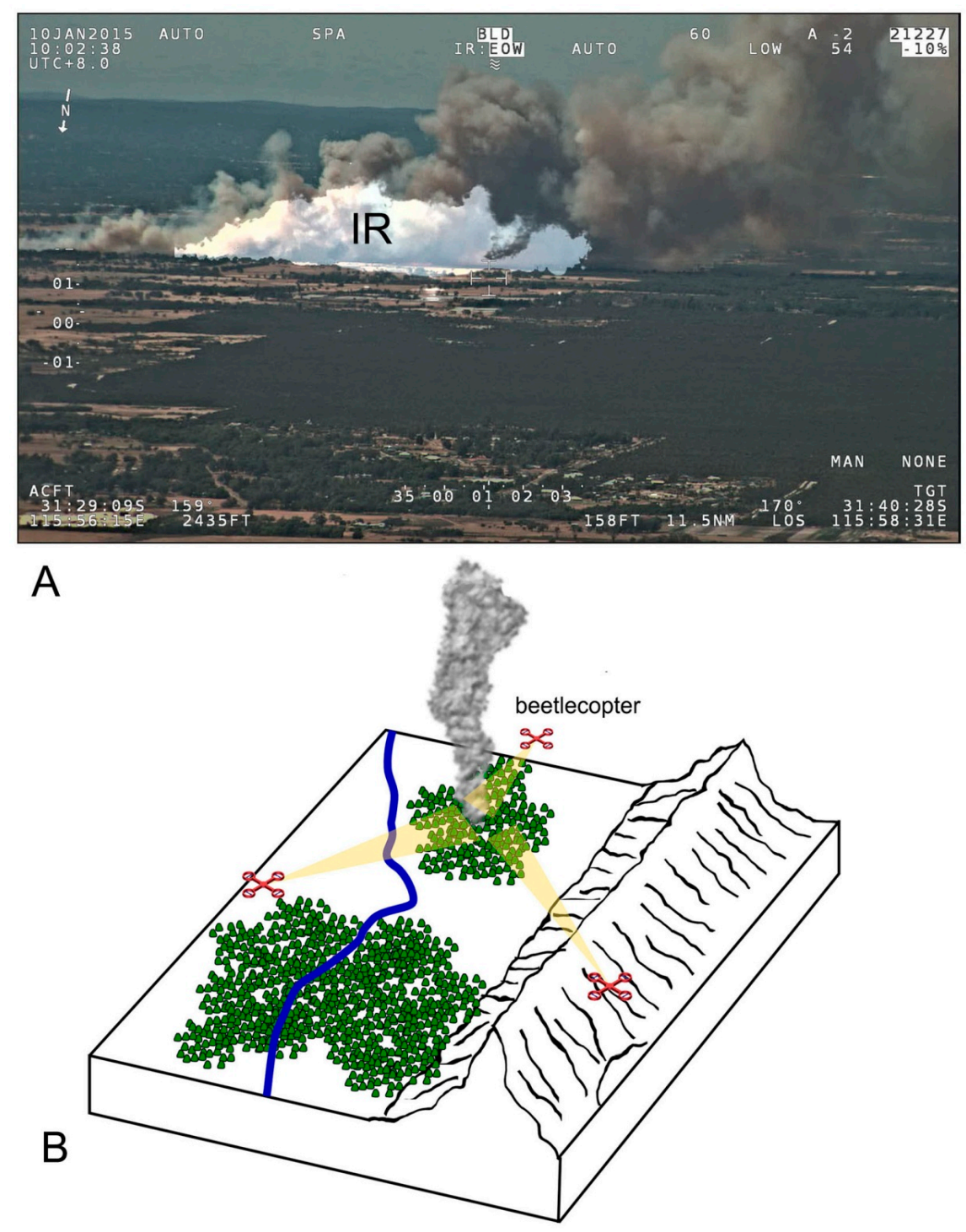

Figure 19. (A) Image of a large forest fire taken from a helicopter from a distance of $21 \mathrm{~km}$ with a WESCAM MX-15 in Western Australia. The image consists of two superimposed pictures: one taken with a high-resolution video camera and one taken with an infrared (IR) camera (white area "IR" showing the hot infrared emission zone of the ongoing fire). Image courtesy of Aerial Intelligence Unit of DEFS (see Acknowledgements).

(B) Schematic drawing of three beetlecopter drones hovering over a terrain with a mountain range. From their stationary airborne positions drones identify a fire with on-board digital video and infrared cameras. By sending a set of alerting data to a central earth station the exact position and the current status of the fire can be determined. 
In Figure 19B, how a network of several beetlecopter drones can be used to monitor a given terrain for fires is shown. The communication and control of partly autonomous flying UAVs, even as a swarm, has already been evaluated [62]. If the drones are positioned in a way that the surveillance sectors of three drones overlap, the geographical position of the fire can be determined by triangulation. Drones have to send their data, including GPS information, to a common earth station and the alarm containing all relevant data to start fire extinguishing can be released.

In order to optimally setup the system, the height at which a particular drone has to ascend, has to be programmed for each drone individually. To prevent accidents with other aircrafts, heights should be as low as possible. Thus the maximal flight altitude should be just large enough to enable the drone to monitor its surveillance area without a gap. As mentioned, the detection range of the IR sensor is of great importance for the entire system. If it could be realized that the detection range of the sensor is in the same region as it had been calculated for the biological system (i.e., about $100 \mathrm{~km}$ ), drones could be positioned at distances of $200 \mathrm{~km}$. By this, vast woodlands could be observed for fires with a very low number of beetlecopters. Because costs for, e.g., quadrocopters, are relatively low anyway, positioning of drones at large distances would further reduce the costs for the proposed beetlecopter system.

\section{Acknowledgments}

Figure 19 is published by courtesy of the Aerial Intelligence Unit, Aviation Services, Department of Fire \& Emergency Services (DFES) and Heliwest (based at Jandakot Airport), Perth, Western Australia.

\section{Author Contributions}

Herbert Bousack carried out all calculations and wrote Sections 3 and 4 and parts of Sections 1 and 5. Anke Schmitz and Helmut Schmitz made the morphological and ultrastructural investigations depicted in Section 2, wrote the corresponding Section, and wrote parts of Sections 1 and 5. Thilo Kahl drew Figure 19B.

\section{Conflicts of Interest}

The authors declare no conflict of interest.

\section{References}

1. Economic Loss due to Mayor Forest and Wildfires Worldwide from 1900 to 2014; Centre for Resarch on the Epidemology of Desasters (CRED): Brussels, Belgium, 2014.

2. Ashe, B.; McAneney, K.J.; Pitman, A.J. Total cost of fire in Australia. J. Risk Res. 2009, 12, 121-136.

3. Hirschberger, P. Wälder in Flammen-Ursachen und Folgen der Weltweiten Waldbrände; World Wildlife Fund Berlin: Berlin, Germany, 2011. (In German)

4. Lloret, J.; Garcia, M.; Bri, D.; Sendra, S. A wireless sensor network deployment for rural and forest fire detection and verification. Sensors 2009, 9, 8722-8747.

5. Alkhatib, A.A.A. A review on forest fire detection techniques. Int. J. Distrib. Sens. Netw. 2014, $2014,597368$. 
6. Martinez-de Dios, J.R.; Merino, L.; Caballero, F.; Ollero, A. Automatic forest-fire measuring using ground stations and unmanned aerial systems. Sensors 2011, 11, 6328-6353.

7. Schmitz, H.; Schmitz, A.; Schneider, E.S. Matched filter properties of infrared receptors used for fire and heat detection in insects. In The Ecology of Animal Senses: Matched Filtering for Economical Sensing; Warrant, G.V.D.E.E., Ed.; Springer-Verlag: Berlin, Heidelberg, Germany, 2015.

8. Bellamy, C.L. A World Catalogue and Bibliography of the Jewel Beetels (Coleoptera: Buprestidae); Pensoft: Sofia, Bulgaria, 2008.

9. Linsley, E.G. Attraction of Melanophila beetles by fire and smoke. J. Econ. Entomol. 1943, 36, 341-342.

10. Apel, K.-H. Die Kiefernprachtkäfer; Forschungsanstalt für Forst und Holzwirtschaft: Eberswalde, Germany, 1991. (In German)

11. Horion, A. Faunistik der mitteleuropäischen Käfer, Bd. 4: Sternoxia (Buprestidae), Fossipedes, Macrodactylia, Brachymera. Entomol; Tutzing (Selbstverlag): München, Germany, 1955. (In German).

12. Evans, W.G. Morphology of the infrared sense organ of Melanophila acuminata (buprestidae: Coleoptera). Ann. Entomol. Soc. Am. 1966, 59, 873-877.

13. Vondran, T.; Apel, K.-H.; Schmitz, H. The infrared receptor of Melanophila acuminata De Geer (Coleoptera: Buprestidae): Ultrastructural study of a unique insect thermoreceptor and its possible descent from a hair mechanoreceptor. Tissue Cell 1995, 27, 645-658.

14. Schmitz, H.; Bleckmann, H. The photomechanic infrared receptor for the detection of forest fires in the buprestid beetle Melanophila acuminata. J. Comp. Physiol. A 1998, 182, 647-657.

15. Schmitz, H.; Mürtz, M.; Bleckmann, H. Infrared detection in a beetle. Nature 1997, 386, 773-774.

16. Schmitz, A.; Sehrbrock, A.; Schmitz, H. The analysis of the mechanosensory origin of the infrared sensilla in Melanophila acuminata (Coleoptera: Buprestidae) adduces new insight into the transduction mechanism. Arthropod Struct. Develop. 2007, 36, 291-303.

17. French, A.S. Mechanotransduction. Ann. Rev. Physiol. 1992, 54, 135-152.

18. Thurm, U.; Erler, G.; Gödde, J.; Kastrup, H.; Keil, T.A. Cilia specialized for mechanoreception. J. Submicrosc. Cytol. 1983, 15, 151-155.

19. Schmitz, H.; Mürtz, M.; Bleckmann, H. Responses of the infrared sensilla of Melanophila acuminata (Coleoptera: Buprestidae) to monochromatic infrared stimulation. J. Comp. Physiol. A Sens. Neural Behav. Physiol. 2000, 186, 543-549.

20. Van Dyke, E.C. Buprestid swarming. Pan Pac. Ent. 1926, 3, 41.

21. Schmitz, H.; Bousack, H. Modelling a historic oil-tank fire allows an estimation of the sensitivity of the infrared receptors in pyrophilous Melanophila beetles. PloS ONE 2012, 7, e37627.

22. Pastor, E.; Zarate, L.; Planas, E.; Arnaldos, J. Mathematical models and calculation systems for the study of wildland fire behaviour. Prog. Energy Combust. Sci. 2003, 29, 139-153.

23. Rossi, J.L.; Chetehouna, K.; Collin, A.; Moretti, B.; Balbi, J.H. Simplified flame models and prediction of the thermal radiation emitted by a flame front in an outdoor fire. Combust. Sci. Technol. 2010, 182, 1457-1477.

24. Sullivan, A.L.; Ellis, P.F.; Knight, I.K. A review of radiant heat flux models used in bushfire applications. Int. J. Wildland Fire 2003, 12, 101-110. 
25. Siegel, R.; Howell, J.R.; Menguc, M.P. Thermal Radiation Heat Transfer, 5th ed.; Taylor and Francis: Oxford, UK, 2010.

26. Knight, I.K.; Sullivan, A.L. A semi-transparent model of bushfire flames to predict radiant heat flux. Int. J. Wildland Fire 2004, 13, 201-207.

27. Cruz, M.G.; Butler, B.W.; Viegas, D.X.; Palheiro, P. Characterization of flame radiosity in shrubland fires. Combust. Flame 2011, 158, 1970-1976.

28. Midgley, S.; Tan, Z. A methodology for determining minimum separation distance between a structure and bushfire hazard. In Proceedings of Bushfire Conference 2006: Life In A Fire-Prone Environment: Translating Science into Practice, Brisbane, Australia, 5-9 June 2006.

29. Wotton, B.M.; McAlpine, R.S.; Hobbs, M.W. The effect of fire front width on surface fire behaviour. Int. J. Wildland Fire 2000, 9, 247-253.

30. Planning for Bushfire Protection-A Guide for Councils, Planners, Fire Authorities, Developers and Home Owners; NSW Rural Fire Service: Sydney, Australia, 2001.

31. Cruz, M.G.; Alexander, M.E.; Wakimoto, R.H. Development and testing of models for predicting crown fire rate of spread in conifer forest stands. Can. J. For. Res. 2005, 35, 1626-1639.

32. Noble, I.R.; Bary, G.A.V.; Gill, A.M. Mcarthur fire-danger meters expressed as equations. Aust. J. Ecol. 1980, 5, 201-203.

33. Construction of Buildings in Bushfire-Prone Areas; Australian Standard 3959; Standards Australia: Sydney, NSW, Australia, 2009.

34. McCaw, W.L.; Gould, J.S.; Cheney, N.P. Existing fire behaviour models under-predict the rate of spread of summer fires in open jarrah (Eucalyptus marginata) forest. Aust. For. 2008, 71, 16-26.

35. Tan, Z.; Midgley, S. A stochastic model for assessing bush fire attack on the buildings in bush fire prone areas In Proceedings of The 18th World IMACS Congress and MODSIM09 International Congress on Modelling and Simulation, Cairns, Australia, 13-17 July 2009; pp. 289-295.

36. Dowdy, A.J.; Mills, G.A.; Finkele, K.; de Groot, W. Australian Fire Weather as Represented by the Mcarthur Forest Fire Danger Index and the Canadian Forest Fire Weather Index; CAWCR Technical Report No. 10; The Centre for Australian Weather and Climate Research: Melbourne, Autralia, 2009.

37. Budzier, H.; Gerlach, G. Thermal Infrared Sensors: Theory, Optimization and Practice; Wiley: West Sussex, UK, 2010.

38. PerkinElmer. Infrared Sensing Technologies 008900_01; PerkinElmer: Waltham, MA, USA, 2009.

39. Hänggi, P. Stochastic resonance in biology-How noise can enhance detection of weak signals and help improve biological information processing. Chem. Phys. Chem. 2002, 3, 285-290.

40. Wiesenfeld, K.; Moss, F. Stochastic resonance and the benefits of noise-From ice ages to crayfish and squids. Nature 1995, 373, 33-36.

41. Adali, T.; Haykin, S.S. Adaptive Signal Processing: Next Generation Solutions; Wiley-IEEE: Hoboken, NJ, USA, 2010.

42. Jafari, M.G.; Chambers, J.A. Adaptrive noise cancellation and blind source separation. In Proceedings of 4th International Symposium on Independent Component Analysis and Blind Signal Separation (ICA2003), Nara, Japan, 1-4 April 2003; pp. 627-632.

43. Johnson, M.T.; Povinelli, R.J. Generalized phase space projection for nonlinear noise reduction. Physica D 2005, 201, 306-317. 
44. Golay, M.J.E. A pneumatic infra-red detector. Rev. Sci. Instrum. 1947, 18, 357-362.

45. Chevrier, J.B.; Baert, K.; Slater, T. An infrared pneumatic detector made by micromachining technology. J. Micromech. Microeng. 1995, 5, 193-195.

46. Kenny, T.W.; Reynolds, J.K.; Podosek, J.A.; Vote, E.C.; Miller, L.M.; Rockstad, H.K.; Kaiser, W.J. Micromachined infrared sensors using tunneling displacement transducers. Rev. Sci. Instrum. 1996, 67, 112-128.

47. Weast, R.C. CRC Handbook of Chemistry and Physics, 1st ed.; CRC Press: Boca Raton, FL, USA, 1988.

48. Szabo, I. Höhere Technische Mechanik: Nach Vorlesungen, 6th ed.; Springer: Berlin, Germany, 2000. (In German)

49. Timoshenko, S.P.; Woinowsky-Krieger, S. Theory of Plates and Shells, 2nd ed.; McGraw-Hill: New York, NY, USA, 1959.

50. Schmitz, H.; Kahl, T.; Soltner, H.; Bousack, H. Biomimetic infrared sensors based on the infrared receptors of pyrophilous insects. Proc. SPIE 2011, 7975, doi:10.1117/12.879149.

51. Soltner, H.; Bousack, H.; Schmitz, H. Zur transienten temperaturentwicklung in einem fluidischen infrarot-detektor aud der basis der infrarotempfindlichen sensillen des schwarzen kiefernprachtkäfers melanophia acuminata. In Proceedings of Mikrosystemtechnik Kongress 2009, Berlin, Germany, 12-14 October 2009; pp. 401-404.

52. Klocke, D.; Schmitz, A.; Soltner, H.; Bousack, H.; Schmitz, H. Infrared receptors in pyrophilous ("fire loving") insects as model for new un-cooled infrared sensors. Beilstein J. Nanotechnol. 2011, 2, 186-197.

53. Nowel, M.S. Functional organization of the metathoracic femoral chordotonal organ in the cricket Acheta domesticus. J. Exp. Biol. 1995, 198, 1977-1988.

54. Understanding Capacitive Position Sensors. Available online: http://www.microsense.net/ caa60b50-cb74-4646-9f8b-2bfbf1ff8d85/resource-center-cps-delivery.htm (accessed on 13 March 2015).

55. Bousack, H.; Banzet, M.; Mayer, D.; Soltner, H. Infrared Sensor Comprising Tunnel Junction Measuring the Deformation of a Membrane. U.S. Patent No. 5,959,200, 28 September 1999.

56. Merino, L.; Caballero, F.; Martinez-de-Dios, J.R.; Maza, I.; Ollero, A. An unmanned aircraft system for automatic forest fire monitoring and measurement. J. Intell. Robot. Syst. 2012, 65, 533-548.

57. Ambrosia, V.G.; Wegener, S.S.; Sullivan, D.V.; Buechel, S.W.; Dunagan, S.E.; Brass, J.A.; Stoneburner, J.; Schoenung, S.M. Demonstrating UAV-acquired real-time thermal data over fires. Photogramm. Eng. Remote Sens. 2003, 69, 391-402.

58. Casbeer, D.W.; Kingston, D.B.; Beard, R.W.; McLain, T.W. Cooperative forest fire surveillance using a team of small unmanned air vehicles. Int. J. Syst. Sci. 2006, 37, 351-360.

59. Sujit, P.B.; Kingston, D.; Beard, R. Cooperative forest fire monitoring using multiple UAVs. In Proceedings of 2007 46th IEEE Conference on Decision and Control, New Orleans, LA, USA, 12-14 December 2007; pp. 4875-4880.

60. Restas, A. Forest fire management supporting by UAV based air reconnaissance results of Szendro fire department, Hungary. In Proceedings of 1st International Symposium on Environment Identities and Mediterranean Area (ISEIMA'06), Corte-Ajaccio, France, 9-12 July 2006; pp. 73-77. 
61. Arrue, B.C.; Ollero, A.; de Dios, J.R.M. An intelligent system for false alarm reduction in infrared forest fire detection. IEEE Intell. Syst. Their Appl. 2000, 15, 64-73.

62. Wietfeld, C. Airborne Remote Sensing for Hazard Inspection by Lightweight Drones (Airshield); BMBF Informationsservice: Berlin, Germany, 2011.

(C) 2015 by the authors; licensee MDPI, Basel, Switzerland. This article is an open access article distributed under the terms and conditions of the Creative Commons Attribution license (http://creativecommons.org/licenses/by/4.0/). 